\title{
Systematic Review on the Efficacy and Safety of Herbal Medicines for Vascular Dementia
}

\author{
Sui Cheung Man, Kam Wa Chan, Jia-Hong Lu, Siva Sundara Kumar Durairajan, \\ Liang-Feng Liu, and Min Li \\ School of Chinese Medicine, Hong Kong Baptist University, Kowloon Tong, Hong Kong \\ Correspondence should be addressed to Min Li, limin@hkbu.edu.hk
}

Received 15 January 2011; Revised 20 April 2011; Accepted 27 May 2011

Academic Editor: Andrew Scholey

Copyright (c) 2012 Sui Cheung Man et al. This is an open access article distributed under the Creative Commons Attribution License, which permits unrestricted use, distribution, and reproduction in any medium, provided the original work is properly cited.

We present a systematic review of existing research that aims to assess the efficacy and safety of herbal medications (HM), as either monotherapy or adjunct to orthodox medications (OM), mainly comprised of cholinesterase inhibitors, for vascular dementia (VaD). We included 47 studies conducted in mainland China, each testing different HM. Of 43 HM monotherapy studies, 37 reported HM to be significantly better than OM or placebo; six reported similar efficacy between HM and OM. All four HM adjuvant studies reported significant efficacy. No major adverse events for HM were reported. Heterogeneity in diagnostic criteria, interventions and outcome measures hindered comprehensive data analysis. Studies suggested that HM can be a safe and effective treatment for $\mathrm{VaD}$, either alone or in conjunction with OM. However, methodological flaws in the design of the studies limited the extent to which the results could be interpreted. Thirty most commonly used herbal constituents, including Rhizoma Chuanxiong (Chuanxiong in Chinese), Radix Polygoni Multiflori (Heshouwu in Chinese) and Radix Astragali (Huangqi in Chinese). were ranked. Further multi-center trials with large sample sizes, high methodological quality and standardized HM ingredients are necessary for clinical recommendations to be made.

\section{Introduction}

Vascular dementia $(\mathrm{VaD})$ is one of the most common forms of dementia after Alzheimer's disease (AD) [1], and the most frequent cause of dementia in the elderly [2]. First described as arteriosclerotic dementia [3], $\mathrm{VaD}$ is defined as loss of cognitive function resulting from ischemic, hemorrhagic brain lesions (such as border zone infarcts and ischemic periventricular leukoencephalopathy) or hypoperfusion, due to cerebrovascular disease or cardiovascular pathology [4]. Incomplete microangiopathic infarcts due to fibrohyalinosis are regarded as the major pathophysiological manifestation [5] of $\mathrm{VaD}$. While $\mathrm{AD}$ is characterized by memory impairment, $\mathrm{VaD}$ is characterized by executive dysfunction [6] and behavioral psychological symptoms such as apathy, abulia, opposition, agnosia [7], anxiety [8], depression [9], and suicidal thoughts [9]. Cognitive impairment is relatively mild as compared to $\mathrm{AD}$.
$\mathrm{VaD}$ accounts for approximately $30 \%$ of dementia in the world today [10]. In Europe, out of 3.7 million of people with clinical dementia, 800,000 have a diagnosis of $\mathrm{VaD}$ [11]. The prevalence rate of $\mathrm{VaD}$ is around $1-4 \%$ in Western developed nations [12]. Recently, in mainland China, a nationwide investigation found the prevalence of $\mathrm{VaD}$ to be around $0.8 \%$ [13]. The total annual cost (direct, illness related and cost arise from informal care) of dementia in developing countries is estimated to be at least USD 73 billion [10]. A study in Denmark revealed the annual cost per demented person to be DKK 77,000 (approximately USD 14,114) [14]. Thus, the total healthcare cost for $\mathrm{VaD}$ patients is highest among all other forms of dementia [15], and the frequency of $\mathrm{VaD}$ is increasing exponentially for people over the age of 65 years old [16]. If current trends continue, $\mathrm{VaD}$ will become an increasingly significant public health problem in the 21 st century. 
Drugs currently used in the treatment of $\mathrm{VaD}$ include cholinesterase inhibitors (donepezil, rivastigmine, and galantamine) [17] and non-cholinergics (memantine, nimodipine, hydergine, nicergoline, CDP-choline, folic acid [18], posatirelin, propentofylline, and pentoxifylline [19]). These orthodox medications (OM) have some efficacy [20]. Preventive therapeutic strategies aiming at reducing cerebrovascular risk factors [17] are also considered by patients likely to develop $\mathrm{VaD}$. As yet, there is no compelling evidence that any of these strategies are effective, and no single intervention can be recommended for the prevention of $\mathrm{VaD}$ [21]. This creates a difficult and frustrating situation for sufferers of the disease, their caregivers, and healthcare providers [18], as well as for healthy people hoping to avoid developing VaD.

Owing to the limitations of $\mathrm{OM}$ and therapeutic prevention, some patients resort to herbal medications (HM). Traditionally, a number of herbs have been used for cognitive disorders. For example, Artemisia absinthium (Wormwood) was used in traditional European medicine to restore cognitive functions [22]. Melissa officinalis (Lemon balm), also widely used in Europe, has been claimed to restore memory [23]. Since the 16th century, Europe, Salvia lavandulaefolia (Spanish sage) and Salvia officinalis (common sage) have been reported as being effective for improving memory [22]. Bacopa monniera (water hyssop) has been used in Ayurvedic medicine to improve memory and intellectual functions. Centella asiatica (Asiatic pennywort), another Ayurvedic remedy, when combined with milk, is also given to improve memory [24]. Withania somnifera root is classed among the rejuvenative tonics in Ayurvedic medicine and is known to sharpen memory [25]. Codonopsis pilosula root (Dangshen in Chinese), Biota orientalis leaves (Cebaiye in Chinese), and Polygala tenuifolia root (Yuanzhi in Chinese) have been used in traditional Chinese medicine (TCM) for amnesia $[26,27]$. Some compounds with cognitionimproving properties have been isolated from various plants. EGb 761, an extract from the leaves of the tree Ginkgo biloba, originally used in Western medicine for circulatory disorders [28], shows reversal of decline in cognitive function and of cerebral insufficiency in numerous studies [29], and is now mainly used in $\mathrm{VaD}$ as well [30]. In another study, hyperforin, isolated from Hypericum perforatum, a herb used in Portuguese folk medicine, appears to enhance cognitive function [31].

In China, a nation with its own system of medicine that has been continuously documented over two thousand years, the incorporation of Chinese herbal medicine (CHM) with Western medicine in the treatment of dementia has become a standard in recent decades. Salvia miltiorrhiza Bge. (Danshen in Chinese) and Pueraria thomsonii Benth. (Gegen in Chinese), commonly used herbs in the Chinese materia medica for the treatment of cardiocerebrovascular symptoms, are well tolerated and effective in improving vascular function and structure. Thus, either one might be able to effectively intervene in the pathophysiological cascade of $\mathrm{VaD}[32]$. An animal study revealed that glossy privet fruit (Ligustrum lucidum Ait.), a kidney-tonifying Chinese herbal medicine, inhibits neural cell apoptosis following the onset of vascular dementia by reducing apoptotic signals induced by cerebral ischemia/hypoxia [33]. A number of proprietary herbal medicines may also be effective for $\mathrm{VaD}$. According to a study, Chunghyul-dan, which possesses therapeutic effects for microangiopathy, could be useful to inhibit the development of $\mathrm{VaD}$ [34]. Huperzine A (HupA), a cholinesterase inhibitor naturally derived from the Chinese herb Lycopodium serratum or Huperzia serrata, has even better penetration through the blood-brain barrier, higher oral bioavailability, and longer duration of AChE inhibitory action than tacrine, donepezil, and rivastigmine [35]. Its anticholinesterase activity is stronger than galantamine (a commonly used drug to treat Alzheimer's disease and various memory impairments) [26]. Its ability to improve memory deficits in elderly people with $\mathrm{VaD}$ and $\mathrm{AD}$ has been demonstrated, with minimal peripheral cholinergic side effects and no unexpected toxicity [35]. These reports suggest that comprehensive investigation of the efficacy and safety of HM is worthwhile; the results could lead to better treatment of $\mathrm{VaD}$ as well as effective prevention.

In a previously conducted systematic review [36], we looked for clinical trials for Alzheimer's disease (AD), and found an even larger number of clinical trials conducted on VaD patients, mainly from mainland China. Because a large proportion of patients have both $\mathrm{VaD}$ and $\mathrm{AD}$ pathologies [37], and because the current OM treatments for both types of dementia are similar, we have systematically reviewed the clinical trials of HM conducted on $\mathrm{VaD}$ patients in this study.

\section{Objective}

This systematic review was conducted to assess the safety and efficacy of HM, as either monotherapy or adjunct to OM in the treatment of $\mathrm{VaD}$.

\section{Method}

3.1. Inclusion Criteria. All published studies reporting randomized, controlled clinical trials comparing HM as monotherapy or adjuvant therapy, with placebo or OM as controls, were included. No restriction on the language of publication was imposed. As there is a lack of a single, specific criterion for the diagnosis of $\mathrm{VaD}$ [38], we accepted the use of the following instruments: Diagnostic and Statistical Manual of Mental Disorders (DSM-III, DSM-III-R [39], and DSMIV [40]), the International Classification of Diseases, 10th Revision (ICD-10) [41]; the State of California Alzheimer's Disease Diagnostic and Treatment Centers (ADDTC) scale [42]; the Hachinski Ischemic Scale (HIS) [43]; the National Institute of Neurological Disorders and Stroke-Association Internationale pour la Recherche et l'Enseignement en Neurosciences scale (NINDS-AIREN) [44]. Trials with participants possessing other forms of dementia (Alzheimer's disease, Lewy body dementia, and frontotemporal dementia) were excluded. There was no restrictions on the ethnicity, gender, age, or disease duration of the participants in the trials. The HM interventions could be either (1) a single herb, (2) a preparation containing multiple herbs, (3) extracts from an herb, or (4) proprietary herbal products. They had 
TABLE 1: Search strategy.

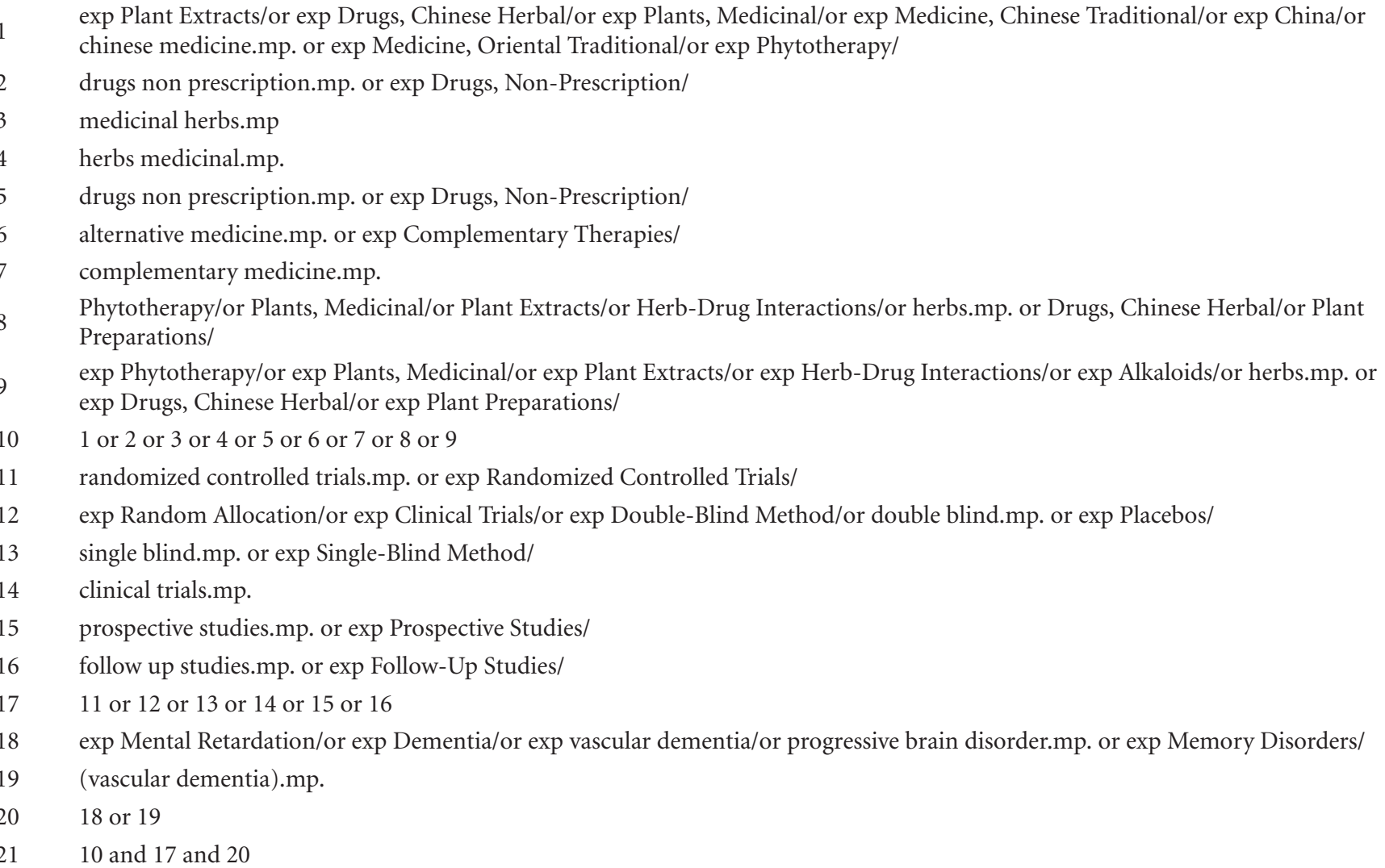

to have been used alone or coadministered with conventional medications (OM). The control intervention had to have been either (1) a placebo, or (2) OM. Trials of all durations were included. Crossover studies were also accepted if the first phase fulfilled the above criteria. Outcome measures of interest were (1) Mini-Mental Status Examination (MMSE) [45], (2) Activities of Daily Living Scale (ADL) [46], and (3) Hasegawa Dementia Scale (HDS) [47]. The safety profile might be represented in (5) adverse effect count, (6) biochemical indications, or (7) number of withdrawals due to adverse events.

3.2. Search Strategy and Method of Review. We identified trials from the following electronic databases: (1) Ovid MEDLINE In-Process and Other Non-Indexed Citations and Ovid MEDLINE; (2) CINAHL; (3) EMBASE; (4) EBM Reviews; (5) AMED; (6) ACP Journal Club; (7) Cochrane Central Register of Controlled Trials; (8) Cochrane Database of Systematic Reviews; (9) Cochrane Methodology Register; (10) Database of Abstracts of Reviews of Effects; (11) Health Technology Assessment; (12) National Health Service Economic Evaluation; (13) China National Knowledge Infrastructure (CNKI); (14) Chinese Sci and Tech Journals (VIP); (15) CBM disc; (16) China Doctor Dissertations FullText Database; (17) China Master Theses Full-text Database. The search conducted in March 2011 followed a strategy (Table 1) developed with reference to a Cochrane review on herbal medicine [48], regardless of language and publication status. Hand-search of a list of Chinese and English journals was carried out to find the latest studies. We also referred to the reference lists of relevant papers to identify potential studies.

Two independent reviewers (K. W. Chan and S. C. Man) assessed the trials for their eligibility. The inclusion of trials was confirmed upon consensus of reviewers. Risk of bias assessment of the trials was performed according to the revised Consolidated Standards of Reporting Trials (CONSORT) statement [49]. Any disagreement was settled by discussion.

\section{Results}

4.1. Description of Included Studies. Using the search strategy as described, 116 studies were identified. Upon full-text examination we excluded 69 , on the basis that (1) 13 were not randomized controlled trials, (2) four were repeat publications, (3) three did not state their inclusion criteria, (4) one included other forms of dementia, (5) 44 did not disclose adequate baseline information, and (6) four involved the use of non-HM intervention, such as acupuncture. These disqualifications left 47 studies for this systematic review.

There were a total of 3725 participants (2423 male, 1302 female) in the 47 included trials. Among them, three had cross-over design while the remaining were parallel design studies. The age of participants ranged from 45-89 years old, and their disease duration ranged from two months to 12 
years. Thirty-two studies were performed in a single center; one was performed in multiple centers; 14 trials did not give this information. The duration of trials lasted from one to seven months. All of the trials were conducted in mainland China, and all the subjects were of Chinese ethnicity.

4.2. Risk of Bias (Table 2). We adopted the checklist of items suggested by CONSORT [50] in the evaluation of methodological quality (risk of bias). The checklist was divided into five sections, namely, title and abstract, introduction, methods, results, and discussion.

Except for 4 studies [51-54], all had adequate information on the title and abstract. Four studies [55-58] did not give an appropriate introduction.

With regard to method, none of the 47 studies reported details for sample size calculations. Eight [51-54, 57, 5961] did not clearly state their objective of study. All but one study [62] poorly reported their randomization and blinding. Statistical method was not reported in 13 studies [51-53, 58, 59, 63-70].

For the results section, only two studies $[62,71]$ reported with a flowchart. Patient recruitment, outcomes and estimation, and ancillary analyses were mentioned by the majority of studies. More than half of the studies did not report adverse event count.

In the discussion section, both the interpretation and overall evidence were adequately reported by the studies; generalizability, however, was not sufficiently illustrated by 13 studies.

4.3. Randomization (Table 2). All of the included studies claimed to have allocated participants randomly to study groups. Six [72-77] reported the use of computer-generated sequences; the other 41 studies did not provide any description of how randomization was achieved.

4.4. Allocation Concealment (Table 2). Except for one study [71] which clearly stated that it did not use any blinding methods, 32 studies did not report whether they applied blinding or not. For those studies which reported the use of allocation concealment, 6 were single blind $[52,57,66,78-$ $81]$, and 8 were double blind $[55,56,62,76,82-85]$.

4.5. Eligible Criteria (Table 3). Only two studies [82, 86] used a single diagnostic criterion to select participants. Other studies used two or more diagnostic criteria. Among them DSM III and IV were the most commonly adopted (42 studies used it) $[39,40]$. The other criteria commonly used, listed in descending order of frequency, were HIS [43] (27 studies), MMSE [45] (25 studies); HDS [47] (17 studies); ADL [46] (11 studies); clinical dementia rating scale (CDR) [87] (6 studies); NINDS-AIREN [44] (five studies); ICD-10 [41] (four studies). Other measurement scales used included the scale for the differentiation of syndromes of vascular dementia (SDSVD) [88], Functional Activities Questionnaire (FAQ) [89], and self-derived criteria (SELF). Furthermore, some studies also carried out diagnostic imaging such as CT and magnetic resonance imaging (MRI) for participant selection.
4.6. Baseline Characteristics and Outcome Measures (Table 3). A number of batteries were employed to evaluate the baseline characteristics and outcome measures. The most commonly employed set of evaluative questionnaires included MMSE [45] (38 studies); HDS [47] (23 studies); ADL [46] (20 studies); Berg Balance Scale (BBS 8 studies); SELF (5 studies); memory quotient (MQ 1 study); geriatric dementia scale (GDS 1 study). Moreover, diagnostic imaging such as electroencephalography (EEG 6 studies) and CT (2 studies) were carried out. A number of studies also took into account the changes in hemodynamics (21 studies) and transcranial doppler (TCD 3 studies) as part of the outcome measures. Lastly, biochemical analysis, such as changes in the level of superoxidase dismutase (SOD), malondialdehyde (MDA), homocysteine ( $\mathrm{HCY})$, testerone $(\mathrm{T})$, and 17 beta-estradiol (E2) were also adopted in assessing the efficacy and safety of interventions in the studies.

The different batteries used in the studies resulted in variation in outcome measures. As the data were not suitable for meta-analysis, only qualitative appraisal could be carried out.

4.7. Herbal Medicine as Monotherapy (Table 3). There were altogether 43 trials testing herbal medicine as a monotherapy for VaD. Among them 15 studies compared different HM preparations with Piracetam alone (a nootropic agent). One study compared HM with another stronger nootropic compound Aniracetam. One study compared HM with Piracetam + hydergine and one study compare HM with Piracetam + Vitamin E + respiratory stimulant Duxil (Almitrine). Hydergine, (also known as ergoloid mesylates, another nootropic agent), was tested alone against HM in 11 studies. Five studies reported HM having similar efficacy to these nootropics; the remaining 23 claimed HM to be significantly better.

Seven studies compared HM with Duxil (Almitrine) alone, a respiratory stimulant originally used to treat patients with chronic obstructive pulmonary disease. In one study, HM is compared with Duxil + Nimodipine (a dihydropyridine calcium channel blocker for the treatment of high blood pressure). One study reported HM to have similar efficacy with Duxil; the other seven claimed that HM is better than Duxil.

Furthermore, HM was compared with Nimodipine in two studies, Huperzine A in one study, cerebroprotein hydrolysate in one study, and placebo in three studies. All of these studies concluded that HM is better than the control intervention.

4.8. Herbal Medicine as an Adjunct Therapy (Table 3). Four trials evaluated $\mathrm{HM}$ as an adjunct therapy for VaD. Two of them evaluated the adjunct effect of the CHM decoction BuYangHuanWuTang. Wang compared it with the coadministration of Piracetam and Nimodipine; Yan compared it with the co-administration of Aniracetam, Nimodipine, together with the injection of cerebroprotein hydrolysate. Shi and Wang studied the CHM decoction which, according to TCM theory, could "tonify the kidney, activating blood," and tested its adjunct effect with nimodipine + hydergine (In 


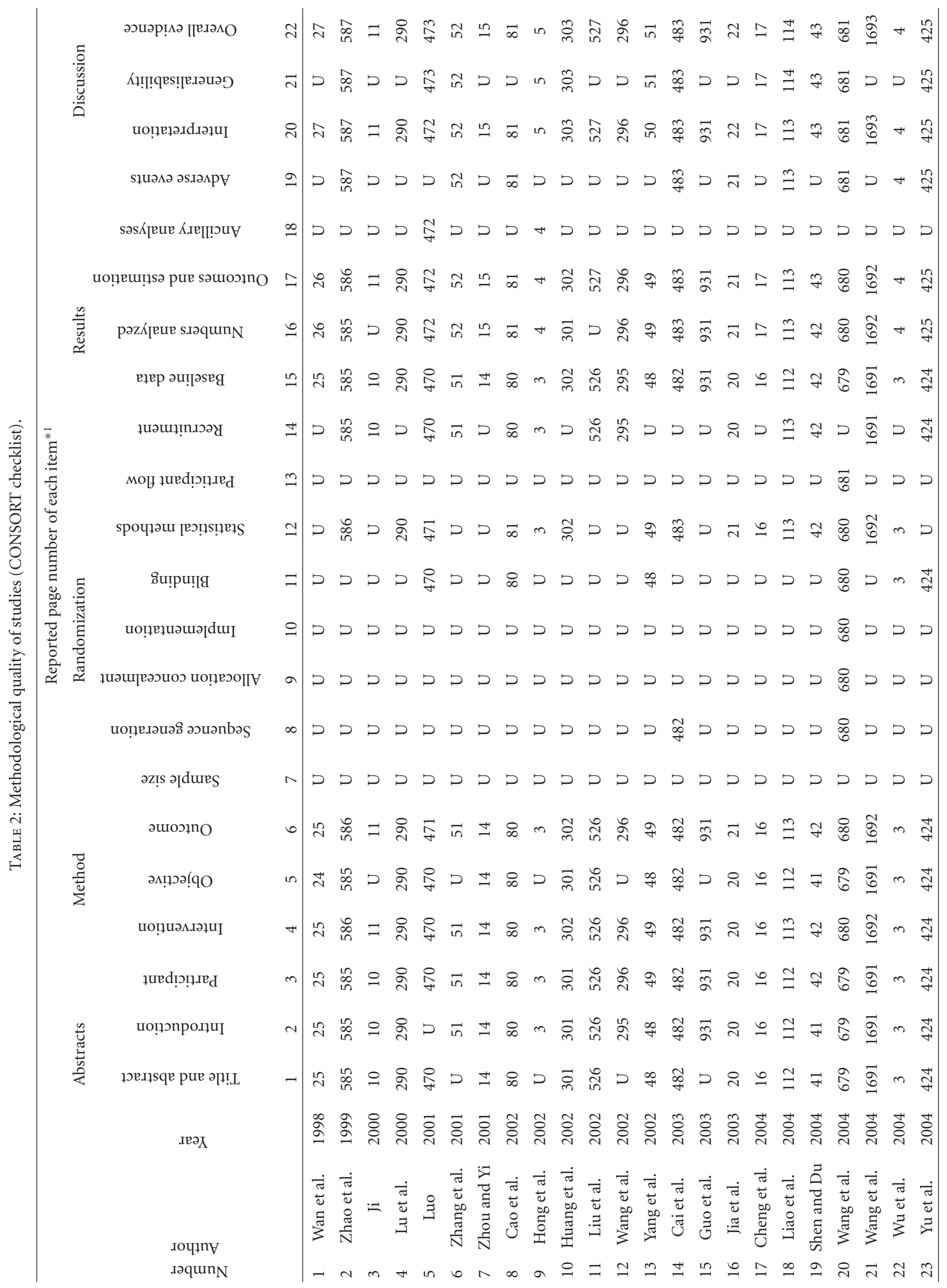




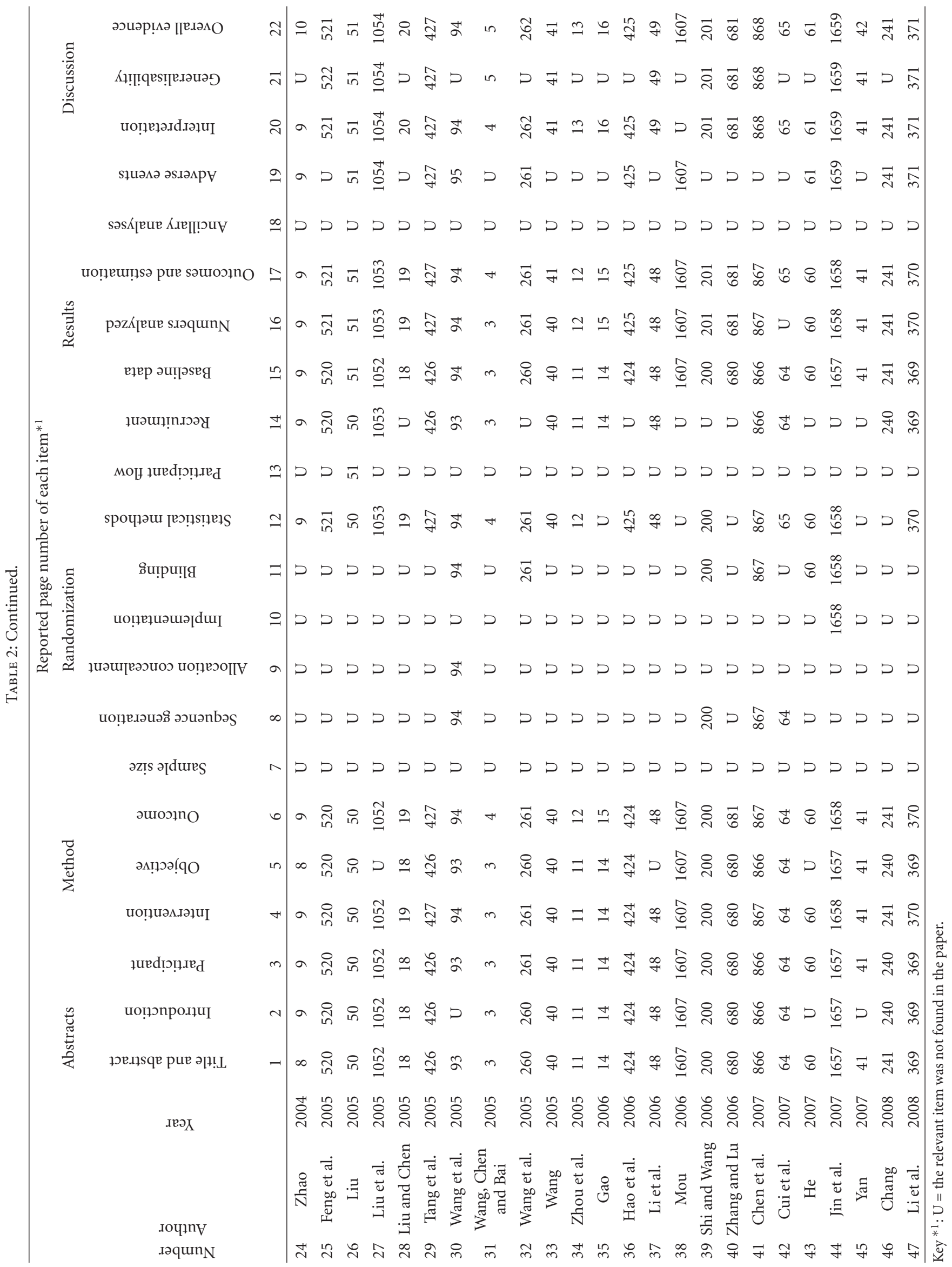




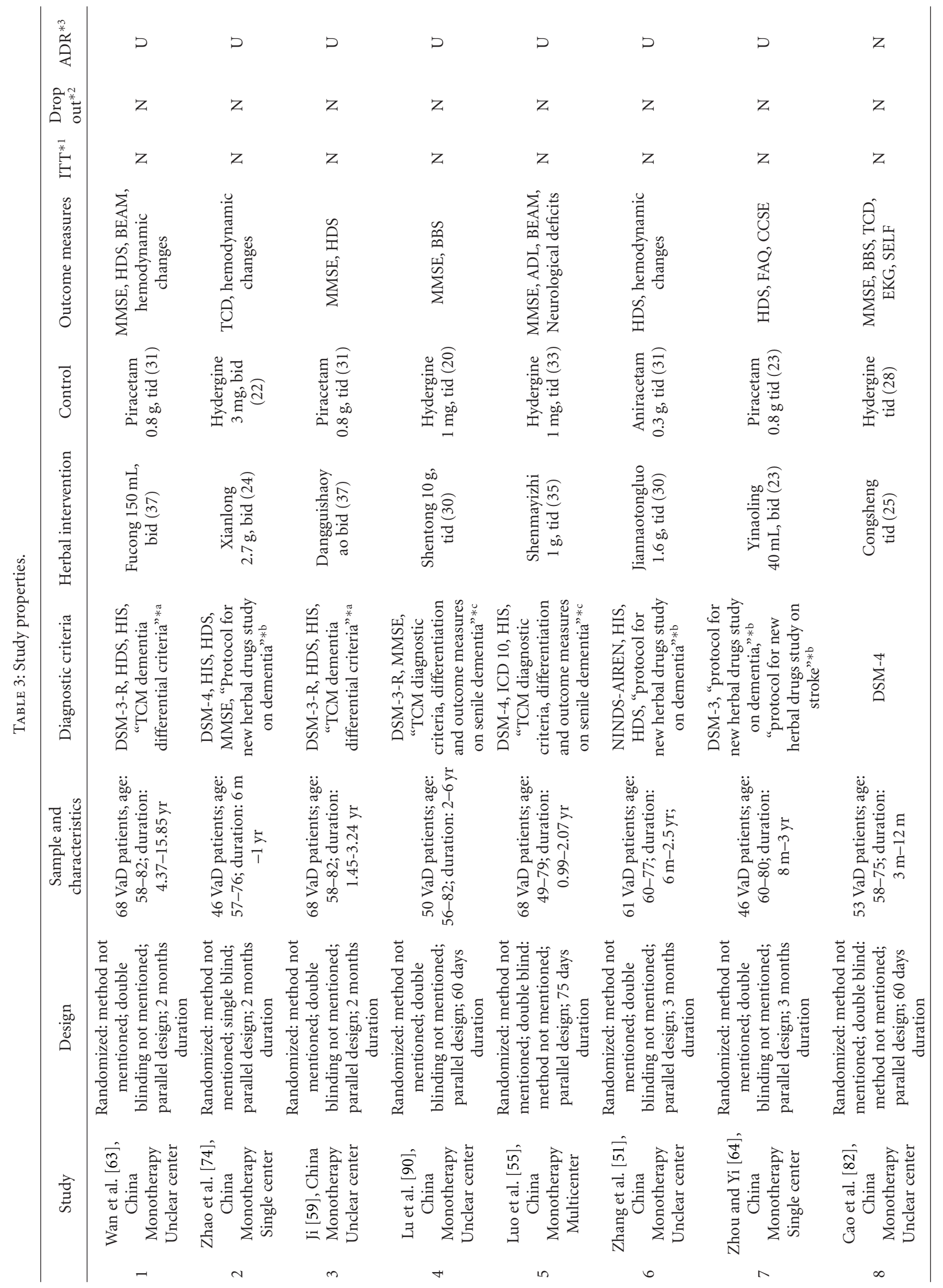




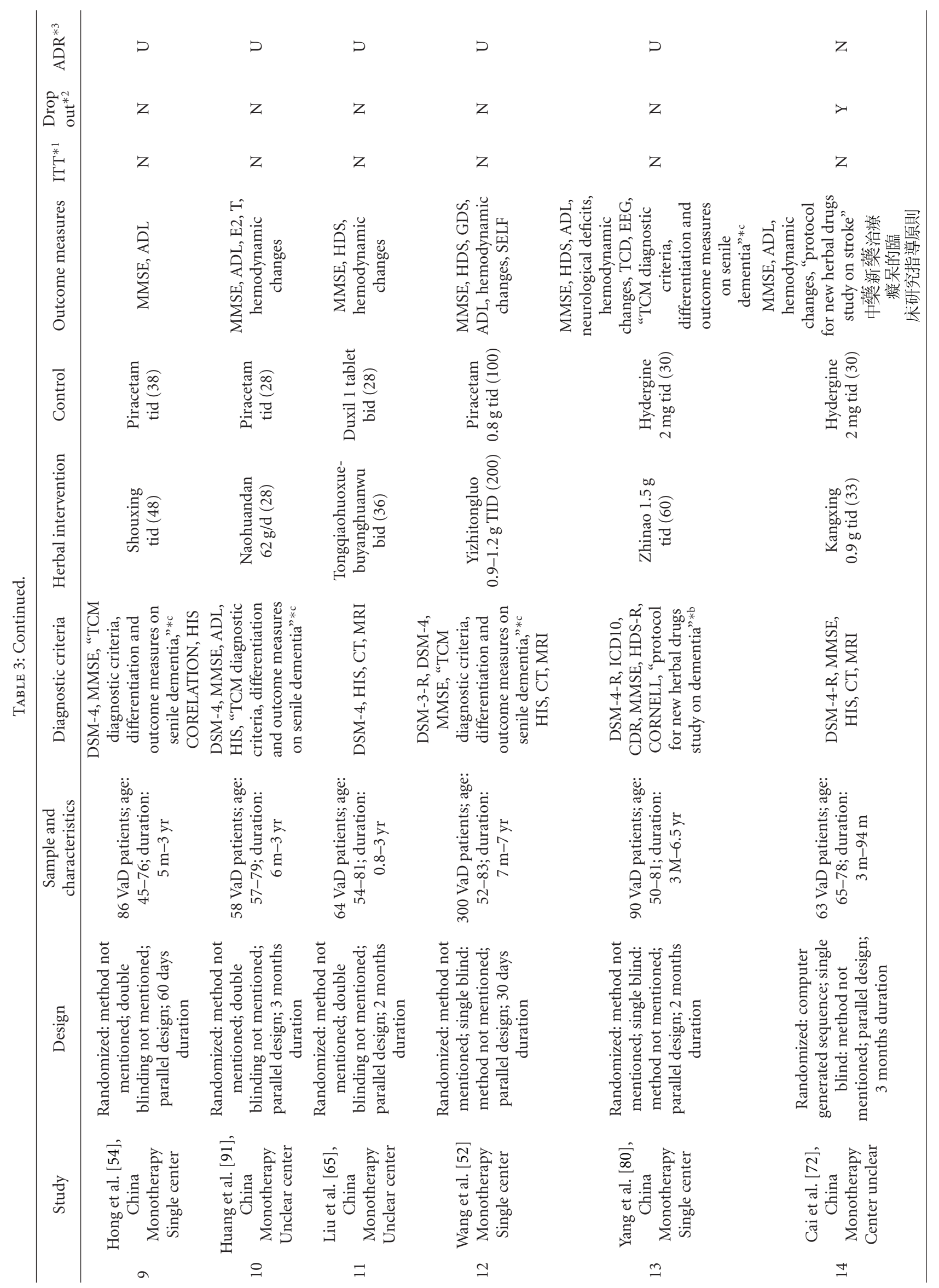




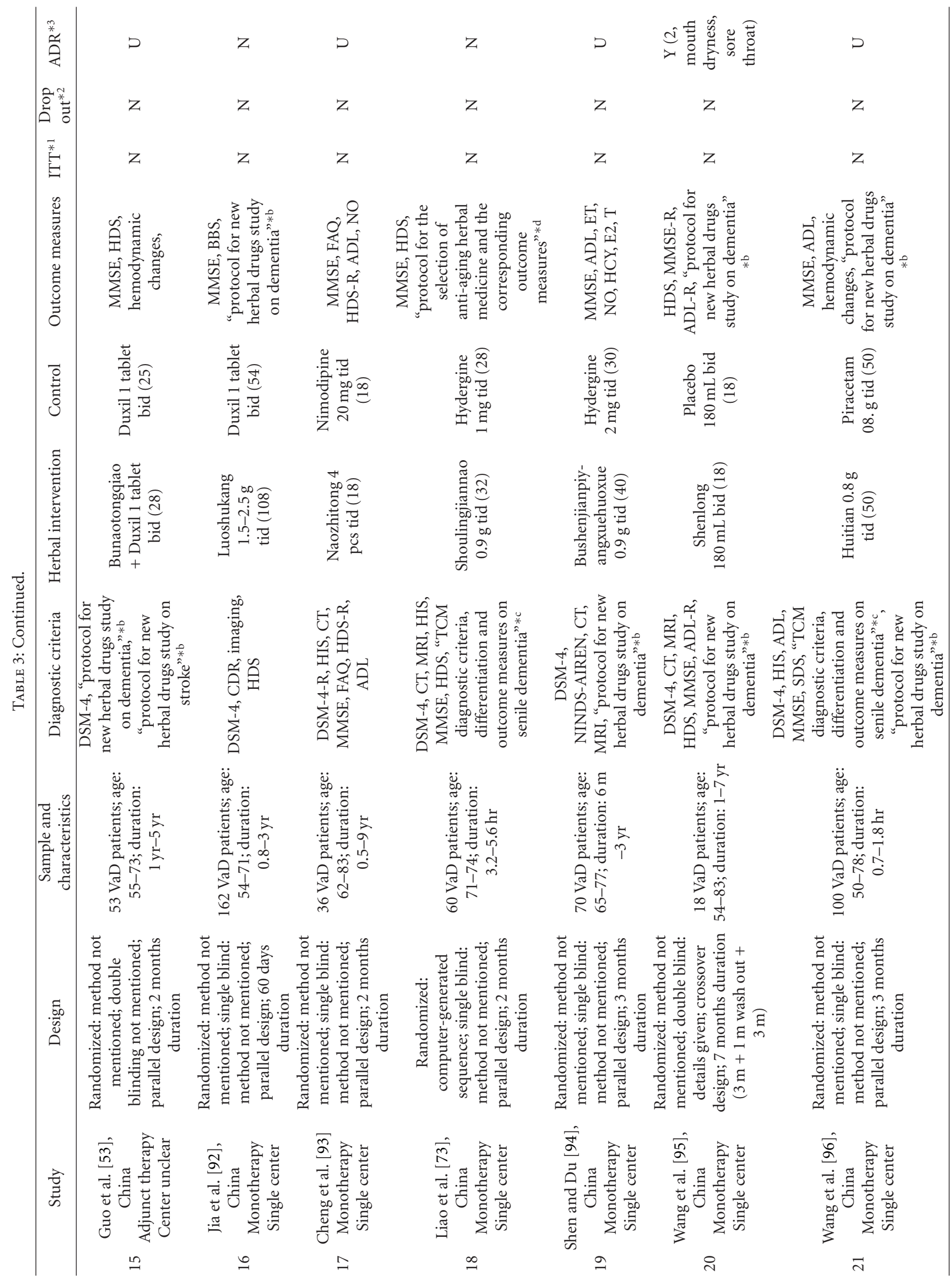




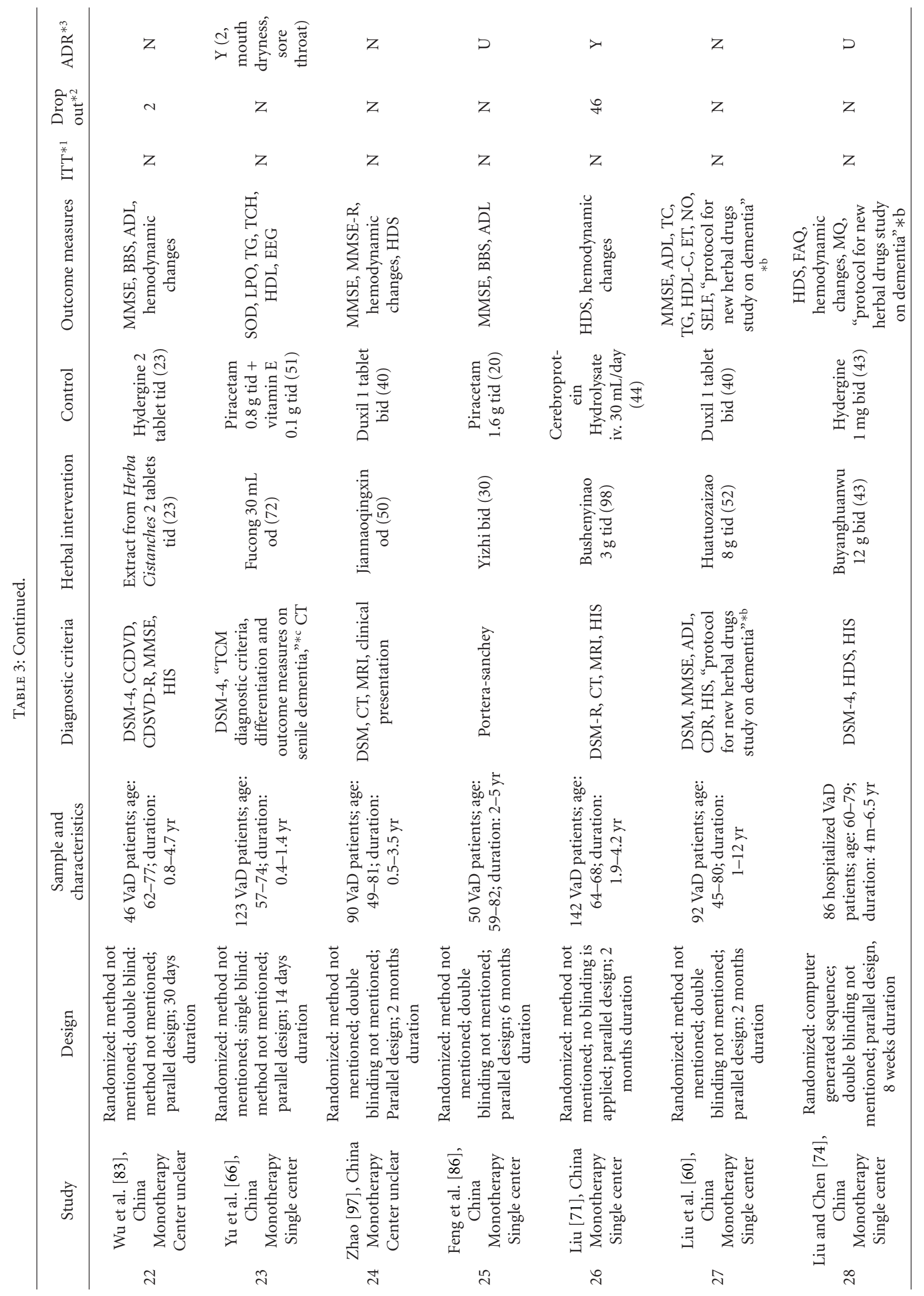




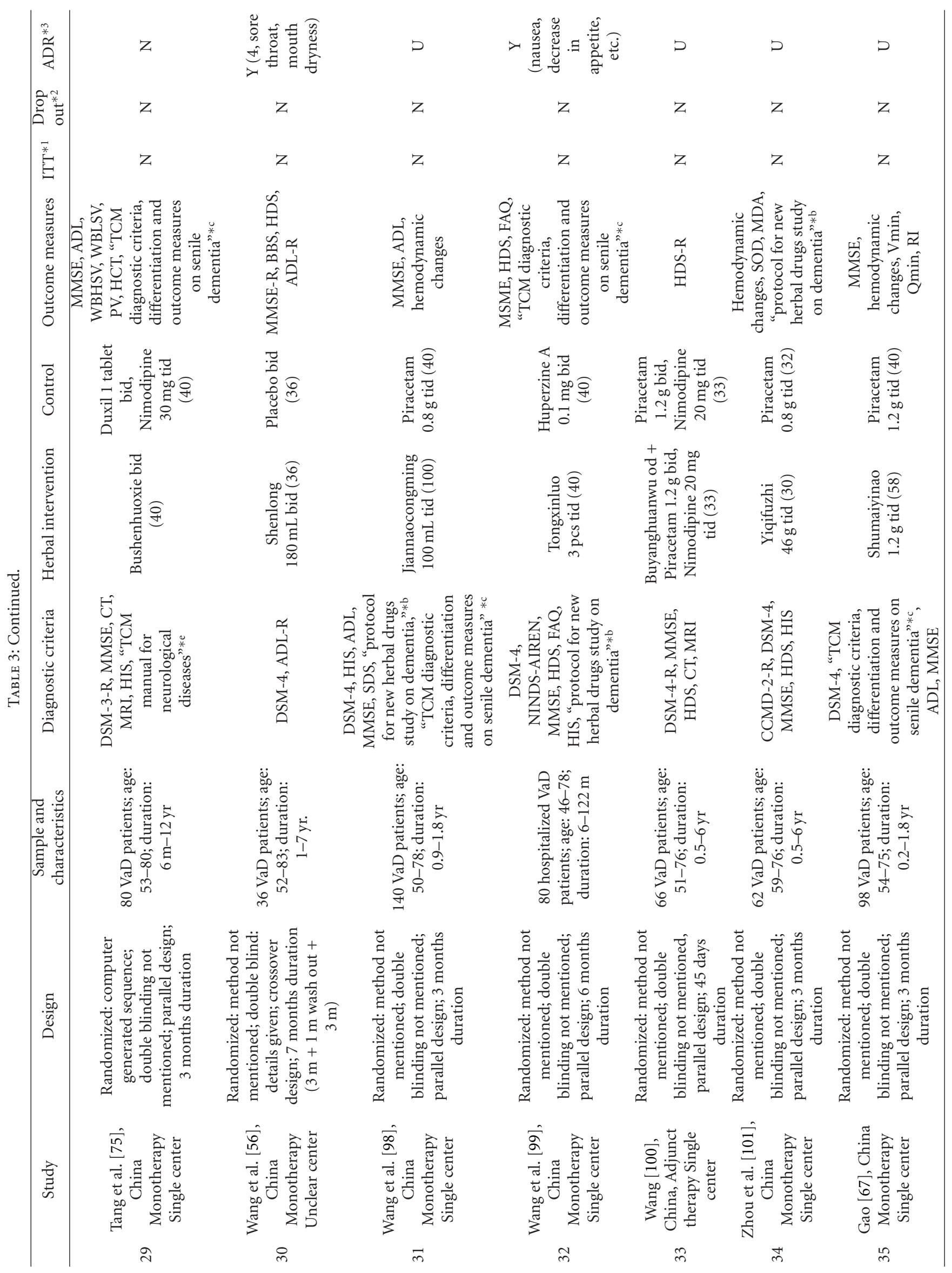




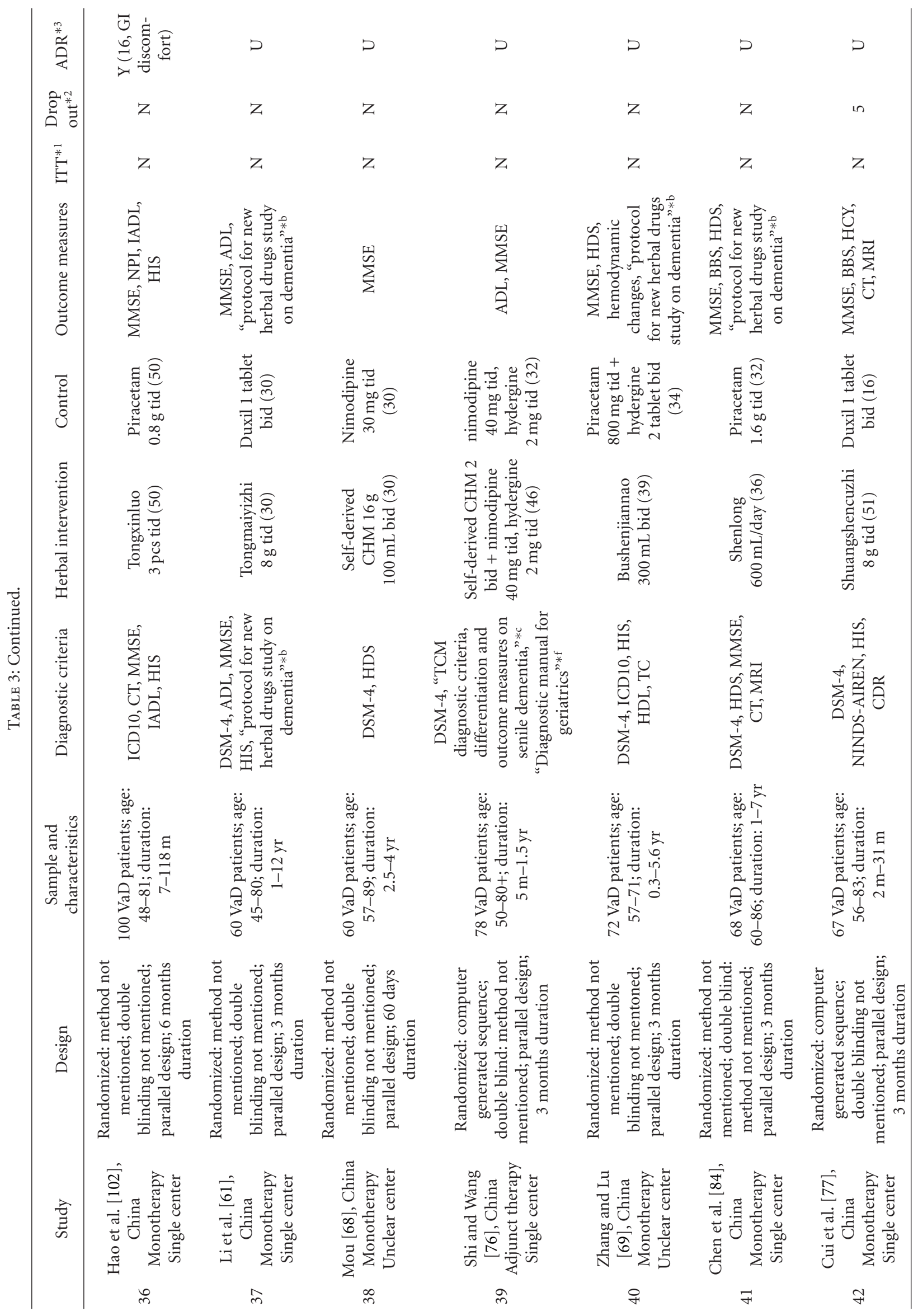




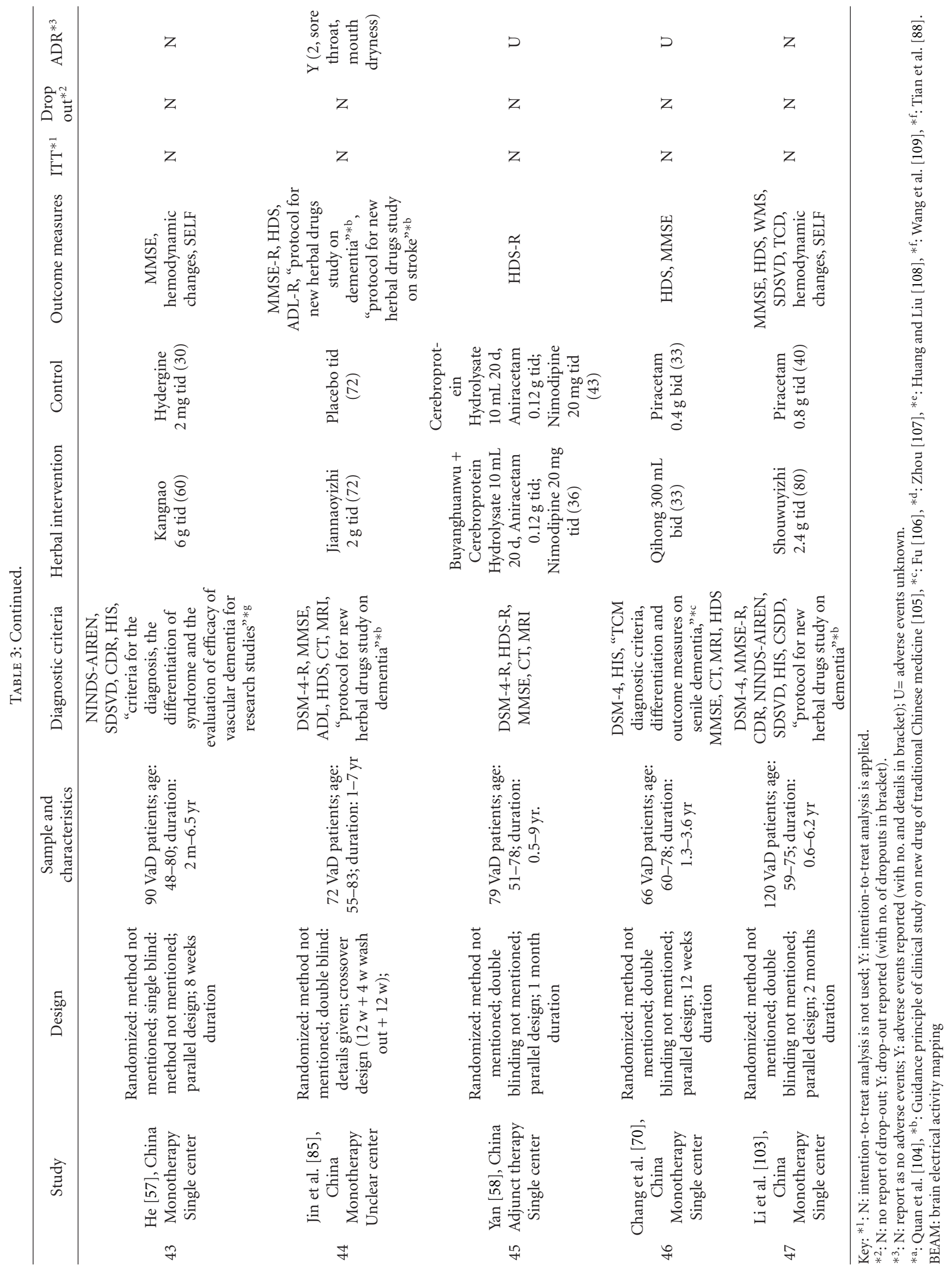


TABle 4: Statistics on herbal intervention.

\begin{tabular}{|c|c|c|c|c|c|}
\hline Number & Chinese name & English name & $\begin{array}{c}\text { Form of } \\
\text { preparation }\end{array}$ & Frequency & Study \\
\hline 1 & 補陽還五 & Buyanghuanwu & Decoction/capsule & 3 & $\begin{array}{l}\text { Liu and Chen [74]; Wang } \\
{[56] ; \text { Yan [58] }}\end{array}$ \\
\hline 2 & 參龍 & Shenlong & Decoction & 3 & $\begin{array}{l}\text { Wang et al. [62]; Wang et } \\
\text { al. [56]; Chen et al. [84] }\end{array}$ \\
\hline 3 & 通心絡 & Tongxinluo & Capsule & 2 & $\begin{array}{l}\text { Wang et al. [99]; Hao et al. } \\
\qquad[102]\end{array}$ \\
\hline 4 & 仙龍 & Xianlong & Capsule & 1 & Zhao et al. [74] \\
\hline 5 & 復聮 & Fucong & Decoction & 1 & Wan et al. [63] \\
\hline 6 & 當歸苟藥 & Dangguishaoyao & Decoction & 1 & Ji [59] \\
\hline 7 & 神通 & Shentong & Capsule & 1 & Lu et al. [90] \\
\hline 8 & 參麻益智 & Shenmayizhi & Capsule & 1 & Luo [55] \\
\hline 9 & 健腦通絡 & Jiannaotongluo & Capsule & 1 & Zhang et al. [51] \\
\hline 10 & 益腦 & Yinaoling & Oral liquid & 1 & Zhou and Yi [64] \\
\hline 11 & 聰聖 & Congsheng & Capsule & 1 & Cao et al. [82] \\
\hline 12 & 尋星 & Shouxing & Capsule & 1 & Hong et al. [54] \\
\hline 13 & 腦還丹 & Naohuandan & Capsule & 1 & Huang et al. [91] \\
\hline 14 & 通憿活血 -補陽還五 & $\begin{array}{l}\text { Tongqiaohuoxue- } \\
\text { buyanghuanwu }\end{array}$ & Decoction & 1 & Liu et al. [65] \\
\hline 15 & 益智通絡 & Yizhitongluo & Capsule & 1 & Wang et al. [52] \\
\hline 16 & 智腦 & Zhinao & Capsule & 1 & Yang et al. [80] \\
\hline 17 & 康欣 & Kangxing & Capsule & 1 & Cai et al. [81] \\
\hline 18 & 補腦通㜔 & Bunaotongqiao & Decoction & 1 & Guo et al. [53] \\
\hline 19 & 絡舒康 & Luoshukang & Capsule & 1 & Jia et al. [92] \\
\hline 20 & 腦智通 & Naozhitong & Capsule & 1 & Cheng et al. [93] \\
\hline 21 & 首靈健腦 & Shoulingjiannao & Capsule & 1 & Liao et al. [73] \\
\hline 22 & 補腎健脾養血活血 & Bushenjianpiyangxuehuoxue & Decoction & 1 & Shen and Du [94] \\
\hline 23 & 回天 & Huitian & Tablet & 1 & Wang et al. [96] \\
\hline 24 & 蓯蓉總式 & Extract from Herba Cistanchis & Herbal extract & 1 & Wu et al. [83] \\
\hline 25 & 復聰香 & Fucongxiang & Oral liquid & 1 & Yu et al. [66] \\
\hline 26 & 健腦清心 & Jiannaoqingxin & Decoction & 1 & Zhao 2004 \\
\hline 27 & 益智 & Yizhi & Decoction & 1 & Feng et al. [86] \\
\hline 28 & 補腎益腦 & Bushenyinao & Capsule & 1 & Liu $[71]$ \\
\hline 29 & 華佗再造 & Huatuozaizao & Tablet & 1 & Liu et al. [60] \\
\hline 30 & 補腎活血 & Bushenhuoxie & Decoction & 1 & Tang et al. [75] \\
\hline 31 & 健腦聰明 & Jiannaocongming & Oral liquid & 1 & Wang et al. [98] \\
\hline 32 & 益氣復智 & Yiqifuzhi & Granule & 1 & Zhou et al. [101] \\
\hline 33 & 舒脈益腦 & Shumaiyinao & Capsule & 1 & Gao [67] \\
\hline 34 & 通脈益智 & Tongmaiyizhi & Tablet & 1 & Li et al. [61] \\
\hline 35 & 益智湯 & Self-derived CHM 1 & Decoction & 1 & Mou [68] \\
\hline 36 & 補腎活血自擬方 & Self-derived CHM 2 & Decoction & 1 & Shi and Wang [76] \\
\hline 37 & 補腎健腦 & Bushenjiannao & Decoction & 1 & Zhang and Lu [69] \\
\hline 38 & 隻參促智 & Shuangshencuzhi & Granule & 1 & Cui et al.[77] \\
\hline 39 & 康腦 & Kangnao & Tablet & 1 & $\mathrm{He}$ [57] \\
\hline
\end{tabular}


TABle 4: Continued.

\begin{tabular}{lclccc}
\hline Number & Chinese name & English name & Form of & Frequency & Study \\
\hline 40 & 健腦益智 & Jiannaoyizhi & Capsule & 1 & Jin et al. [85] \\
41 & 芪紅 & Qihong & Oral liquid & 1 & Chang et al. [70] \\
42 & 首烏益智 & Shouwuyizhi & Capsule & 1 & Li et al. [103] \\
\hline
\end{tabular}

TCM theory, the brain is considered an outgrowth of "kidney" energy. Neurodegenerative disorders such as dementia are caused by stagnation of "blood," accumulation of "phlegm," and deficiency of the "kidney." In order to resist or halt the condition, TCM treatment targets the nourishment of the kidney by means of "kidney invigorating," "blood activating" and "phlegm dissipating" herbal decoctions [110]. Guo et al. [53] studied another CHM BuNaoTongQiao decoction, which possesses nootropic properties, according to TCM theory, and compared it with Duxil. All these studies reported that when HM is used together with Western medications, both the efficacy and safety of OM could be enhanced.

4.9. Adverse Events and Withdrawal (Table 3). Among those 43 studies which tested HM as monotherapy, 25 studies did not report any cases of withdrawal. Ten studies claimed they did not observe any adverse events in groups treated with HM. Eight studies reported a number of mild adverse events, such as mouth dryness, sore throat, constipation, nausea, loss of appetite, and dyspepsia. These adverse events could be resolved without treatment. Serious adverse events were not observed. Occurrence of adverse events remained unclear in the four studies which tested HM as adjunct therapy.

The dropouts or withdrawals were unclear in 44 out of 47 studies. Wu et al. [83] reported two dropouts in the course of intervention. Liu et al. [71] reported 46 dropouts during his trial. Cui et al. [77] reported five dropouts.

\section{Discussion}

5.1. A Wide Variety of Herbal Remedies. Thirty-one out of 47 studies tested herbal mixtures prepared in the form of granules or capsules. Fifteen studies tested their herbal mixtures in the form of decoctions. One study tested the extract from a single herb. As some of the studies tested the same herbal mixture, altogether 42 different herbal mixtures were tested among these 47 studies (Table 4 ). These herbal mixtures or extracts, according to the TCM theory, have the ability to "tonify the "kidney," activate blood." Despite the absence of pharmacological studies to verify their safety, these studies reported encouraging effects and high safety profiles. Upon further analysis of the constitutional ingredients in these herbal formulas, we ranked the 30 most commonly used herbal constituents together according to the dosages (Table 5).

The first five in descending order of frequency of use are Rhizoma Chuanxiong (Chuanxiong in Chinese), Radix Polygoni Multiflori (Heshouwu in Chinese), Radix Astragali
(Huangqi in Chinese), Radix Ginseng (Renshen in Chinese), and Rhizoma Acori Tatarinowii (Shichangpu in Chinese).

Rhizoma Chuanxiong, originates from the plant Ligusticum chuanxiong Hort., which is used in TCM to "remove blood stasis." Chemical analysis shows that it possesses an alkaloid named ligustrazine, which has antioxidant, antiinflammatory, antifibrosis, and immune-modulative properties [111]. A clinical study is being carried out to evaluate its effect on patients' recovery from cerebral vascular accidents [112]. The root of Polygonum multiflorum Thunb. (Radix Polygoni Multiflori in English, the Chinese name is Heshouwu), commonly known as fleece flower root, is another popular HM used to treat premature aging and dementia. Past studies have shown it to have activity that may contribute to cardiovascular protection [113]. Longterm pretreatment with it may protect the brain against focal cerebral ischemia [114]. One animal study also suggests that it has anti-oxidant properties [115], with the capacity to prevent cognitive deficits [116], possibly even to promote learning and enhance memory [117]. A medical team in Taiwan is proposing a phase II clinical trial to assess the efficacy and safety of a new drug derived from it [118]. Radix Astragali (Huangqi), from Astragalus membranaceus (Fisch.) Bge. var. mongholicus (Bge.) Hsiao, a commonly used herb to "vitalize spleen Qi" and "treat circulatory disorders" in TCM, possesses various components (astragalus saponins, astragalus polysaccharide) demonstrated to have anti-oxidation properties. These, together with its anti-cholinergic property, have been suggested to be the source of its significant antidementia effect [119]. A clinical trial is being carried out to determine the effect of an HM capsule with Radix Astragali (Huangqi in Chinese) as the main constituent on ischemic stroke [112]. Radix Salviae Miltiorrhizae (Danshen in Chinese), the root of Salvia miltiorrhiza Bge., is used to "activate blood and resolve stasis" according to TCM. A laboratory study of its triterpenoids-enriched extract revealed that its antiatherogenic property was mediated by an anti-inflammatory mechanism [120]. Another animal study of Radix Salviae Miltiorrhizae (Danshen) reports it to reduce the area of cerebral infarct in ischemia-reperfusion injured rats, suggesting it has potential in the treatment of cerebral infarct in humans [121]. Radix Ginseng (Rensheng), the root of Panax ginseng C.A. Mey., is a popular notifying herb in TCM, and its ginsenosides have been found to have protective effects on memory via antiapoptosis in a rat model with vascular dementia [122], and to stimulate angiogenesis and tissue regeneration [123], suggesting that it has potential to help VaD patients. In a Korean clinical study, Radix Ginseng was reported to be clinically effective in improving the 
TABLE 5: The 30 most commonly used herbal constituents.

\begin{tabular}{|c|c|c|c|c|c|c|}
\hline & Chinese name & Scientific name & English name & Latin name & Freq. & Dose $(\mathrm{g})$ \\
\hline 1 & 川芦 & Rhizoma Chuanxiong & Szechwan Lovage Rhizome & $\begin{array}{c}\text { Ligusticum chuanxiong } \\
\text { Hort. }\end{array}$ & 24 & $6-15$ \\
\hline 2 & 何直烏 & Radix Polygoni Multiflori & Fleeceflower root & $\begin{array}{c}\text { Polygonum multiflorum } \\
\text { Thunb. }\end{array}$ & 24 & $10-20$ \\
\hline 3 & 黃芪 & Radix Astragali & Milkvetch root & $\begin{array}{l}\text { Astragalus membranaceus } \\
\quad \text { (Fisch.) Bge. Var. } \\
\text { mongholicus (Bge.) Hsiao }\end{array}$ & 22 & $15-120$ \\
\hline 4 & 丹參 & $\begin{array}{l}\text { Radix Salviae } \\
\text { Miltiorrrhizae }\end{array}$ & Danshen root & Salvia miltiorrhiza Bge. & 14 & $10-20$ \\
\hline 5 & 人參 & Radix Ginseng & Ginseng & Panax ginseng C.A. Mey. & 13 & $6-10$ \\
\hline 6 & 石菖蒲 & Rhizoma Acori Talarinowii & $\begin{array}{c}\text { Grassleaf Sweetflag } \\
\text { Rhizome }\end{array}$ & Acorus tatarinowii Schott. & 13 & $6-10$ \\
\hline 7 & 當歸 & Radix Angelica Sinensis & Chinese Angelica & $\begin{array}{c}\text { Angelica sinensis (Oliv.) } \\
\text { Diels }\end{array}$ & 11 & $6-15$ \\
\hline 8 & 山茱莫 & Fructus Corni & $\begin{array}{l}\text { Asiatic Cornelian Cherry } \\
\text { fruit }\end{array}$ & $\begin{array}{c}\text { Cornus officinalis Sieb. et } \\
\text { Zucc. }\end{array}$ & 10 & $10-15$ \\
\hline 9 & 遠志 & Radix Polygalae & Thinleaf Milkwort root & Polygala tenuifolia Willd. & 10 & $10-12$ \\
\hline 10 & 益智仁 & $\begin{array}{l}\text { Fructus Alpiniae } \\
\text { Oxyphyllae }\end{array}$ & Sharpleaf Galangal fruit & Alpinia oxyphylla Miq. & 9 & $10-15$ \\
\hline 11 & 枸杞子 & Fructus Lycii & Barbary Wolfberry fruit & Lycium barbarum L. & 8 & $10-20$ \\
\hline 12 & 紅花 & Flos Carthami & Safflower & $\begin{array}{l}\text { Carthamus tinctorius L.; } \\
\text { Crocus sativus L. }\end{array}$ & 8 & $3-5$ \\
\hline 13 & 黃精 & Rhizoma Polygonati & Solomonseal Rhizome & $\begin{array}{l}\text { Polygonatum sibiricum } \\
\text { Red.; P. cyrtonema Hua; } P \text {. } \\
\text { kingianum Coll. et Hemsl. }\end{array}$ & 8 & $15-30$ \\
\hline 14 & 九節菖蒲 & $\begin{array}{l}\text { Rhizoma Anemonis } \\
\text { Altaicae }\end{array}$ & Irkutsk Anemone Rhizome & $\begin{array}{c}\text { Anemone altaica Fisch. ex. } \\
\text { C.A. Mey. }\end{array}$ & 8 & $8-12$ \\
\hline 15 & 熟地 & Radix Rehmanniae & Rehmannia root & $\begin{array}{c}\text { Rehmannia glutinosa } \\
\text { Libosch. }\end{array}$ & 8 & $10-20$ \\
\hline 16 & 赤药 & Radix Peaoniae Rubra & Red Peony root & $\begin{array}{c}\text { Paeonia lactiflora Pall.; } P . \\
\text { veitchii Lynch }\end{array}$ & 7 & $6-15$ \\
\hline 17 & 天麻 & Rhizoma Gastrodiae & Tall Gastrodia Tuber & Gastrodia elata $\mathrm{Bl}$. & 6 & $6-10$ \\
\hline 18 & 桃仁 & Semen Persicae & Peach seed & $\begin{array}{l}\text { Prunus persica (L.) Batsch; } \\
\text { P. davidiana (Carr.) Franch. }\end{array}$ & 6 & $3-12$ \\
\hline 19 & 浖羊蕉/仙靈脾 & Herba Epimedii & Epimedium herb & $\begin{array}{c}\text { Epimedium brevicornum } \\
\text { Maxim.; E. sagittatum } \\
\text { (Sieb. et Zucc.) Maxim; E. } \\
\text { pubescens Maxim.; E. } \\
\text { wushanense T.S. Ying; E. } \\
\text { koreanum Nakai }\end{array}$ & 6 & 12 \\
\hline 20 & 缶鼂金 & Radix Curcumae Wenyujin & Turmeric Root Tuber & $\begin{array}{l}\text { Curcuma wenyujin Y. H. } \\
\text { Chen et C. Ling; C. longa } \\
\text { L.; C. kwangsiensis S.G. Lee } \\
\text { et C. F. Liang; C. } \\
\text { phaeocaulis Val. }\end{array}$ & 6 & $10-15$ \\
\hline 21 & 白苟 & Radix Paeoniae Alba & White Peony root & Paeonia lactiflora Pall. & 4 & 15 \\
\hline 22 & 黨參 & Radix Codonopsis & Pilose Asiabell root & $\begin{array}{l}\text { Codonopsis pilosula } \\
\text { (Franch.) Nannf.; C. } \\
\text { pilosula Nannf. var. } \\
\text { modesta (Nannf.) L.T. } \\
\text { Shen; C. tangshen Oliv. }\end{array}$ & 4 & $10-20$ \\
\hline 23 & 女貞子 & Fructus Ligustri Lucidi & Glossy Privet fruit & Ligustrum lucidum Ait. & 3 & 10 \\
\hline 24 & 山藥淮山 & Rhizoma Dioscoreae & Common Yam Rhizome & Dioscorea opposita Thunb. & 3 & $15-30$ \\
\hline
\end{tabular}


Table 5: Continued.

\begin{tabular}{|c|c|c|c|c|c|c|}
\hline & Chinese name & Scientific name & English name & Latin name & Freq. & Dose $(\mathrm{g})$ \\
\hline 25 & 五味子 & $\begin{array}{l}\text { Fructus Schisandrae } \\
\text { Chinensis }\end{array}$ & Chinese Magnoliavine fruit & $\begin{array}{l}\text { Schisandra chinensis } \\
\text { (Turcz.) Baill. }\end{array}$ & 3 & 10 \\
\hline 26 & 巴戟天 & Radix Morindae Officinalis & Morinda root & Morindae officinalis How & 3 & 20 \\
\hline 27 & 半夏 & Rhizoma Pinelliae & Pinellia Tuber & $\begin{array}{c}\text { Pinellia ternate (Thunb.) } \\
\text { Breit }\end{array}$ & 3 & $10-12$ \\
\hline 28 & 白术 & $\begin{array}{l}\text { Rhizoma Atractylodis } \\
\text { Macrocephalae }\end{array}$ & $\begin{array}{c}\text { Largehead Atractylodes } \\
\text { Rhizome }\end{array}$ & $\begin{array}{c}\text { Atractylodes macrocephala } \\
\text { Koidz. }\end{array}$ & 3 & $10-15$ \\
\hline 29 & 肉桂 & Cortex Cinnamomi & Cassia Bark & Cinnamomum cassia Presl & 3 & $\begin{array}{l}\text { Unkno- } \\
\text { wn }\end{array}$ \\
\hline 30 & 肉蓯蓉 & Herba Cistanches & Desertliving Cistanches & $\begin{array}{c}\text { Cistanche deserticola } \\
\text { Y.C.Ma }\end{array}$ & 3 & $10-20$ \\
\hline
\end{tabular}

cognitive performance of AD patients [124]. Rhizoma Acori Tatarinowii (Shichangpu), also named grassleaf or sweet-flag rhizome, the rhizome of Acorus tatarinowii Schott., is used in TCM for resuscitation after coma. Pharmacological studies suggest this effect may be due to the increase in permeability of the blood-brain barrier [125]. In another pharmacological study, the fruit of Cornus officinalis Sieb. et Zucc. (Shanzhuyu in Chinese), which is used in TCM to "tonify the kidney," was found to possess an extract that has protective effects against oxidative stress-induced neurotoxic processes [126]. Other experimental reports have indicated that the triterpenoid saponins from the roots of Polygala tenuifolia Willd. (Yuanzhi) possess neuroprotective effects [127, 128]. Study on extracts of Alpiniae Oxyphyllae Miq. (Fructus Alpinae Oxyphyllae in English, the Chinese name is Yizhi) have found evidence that it protects neurons against ischemia-induced cell death [129] and that it prevents glutamate-induced apoptosis in cortical neurons [130]. In another study, it was reported that Rhizoma Polygonati (known as Huangjing in Chinese, used in TCM as a notifying agent) could improve learning and memory in a scopolamine-induced mouse model of dementia by reducing the damaging effects of cerebral ischemia and anti-oxidation, having similar effects to those provided by vitamin $\mathrm{E}$ [131]. In a study to examine the anti-oxidative and neuroprotective effects of Paeonia lactiflora Pall. (Baishao in Chinese), it was found to suppress the hydrogen peroxide-induced apoptosis in PC12 cells, suggesting that it could be a new antioxidant useful in the prevention of neuronal diseases [132]. Rhizoma Gastrodiae from Gastrodia elata Bl. (Tianma in Chinese), a classic HM used to "extinguish wind and arrest convulsions" in TCM theory, possesses vasodilating [133], anti-inflammatory, and antiangiogenic activities [134], suggesting a potential $\mathrm{VaD}$ treatment. The total alkaloids found in Radix Codonopsis (Dangshen in Chinese used in TCM to "tonify Qi") have been reported to potentiate neurite outgrowth induced by nerve growth factor in PC12 cells [135]. Glossy privet fruit, from Ligustrum lucidum Ait. (Nüzhenzi in Chinese), a kidney-tonifying HM, can inhibit cell apoptosis by reducing apoptotic signals induced by cerebral ischemia/hypoxia [33].
5.2. Study Weaknesses. Though all the studies reported promising results of $\mathrm{HM}$ in the treatment of $\mathrm{VaD}$, they demonstrated a number of weaknesses as well. The evidence drawn from the studies was insufficient for us to confirm the safety and efficacy of HM, because of the following issues

(1) The sample sizes of the studies ranged from 18 to 300 , and none of them reported sample size calculations, as suggested by the CONSORT statement. Treatment effects can be exaggerated when sample size is inappropriate, and thus the results of these studies may not be conclusive.

(2) Different diagnostic criteria were used in the studies. Some of these criteria were even self-derived and their validities remained unknown. This produced much discrepancy.

(3) Differences in the baseline characteristics of the subjects limit the extent to which results can be compared with each other.

(4) Though all of the studies claimed to have participants allocated randomly, only a few reported the method of randomization. For those studies without detailed descriptions of randomization, we could not rule out the possibility of bias. Furthermore, unclear descriptions of allocation concealment, dropouts, and intention-to-treat analysis further hamper the ability to assess the validity of the evidence reported by these studies.

(5) Outcome measures varied and were incomplete in the studies. Some investigators employed self-developed scales, which could not be, or had not been, independently evaluated for their sensitivity and specificity. The validity is further questionable due to insufficient or inappropriate statistical treatment. Though metaanalysis techniques such as vote-counting may have been used for the analysis of the data, we avoid to do so because (1) the statistical significance or size of the results of the individual studies are ignored; and (2) vote-counting takes no account of the differential weights given to each study. [136] 
(6) Different HM were tested in the 47 studies included here, with great variation in terms of composition, dosage, and duration of interventions. This renders comparison of the studies impossible, and thus quantitative analysis could not be carried out.

(7) A number of studies (30 out of 47) did not mention safety issues. The investigators of these studies may have underestimated possible adverse events, and the safety of HM in these studies could not be guaranteed.

5.3. Implications for Further Studies. Regarding the published studies, methodology quality is the leading should concern. It is recommended that future clinical studies follow the guidelines as suggested by CONSORT to minimize bias as well as to ensure high validity, statistically reliable results and to permit comparison with other studies. Researchers should explicitly report methods for calculation of sample size. Widely recognized diagnostic criteria and outcome measures should be used. It is highly recommended to incorporate medical imaging techniques (such as perfusion computed tomography) to confirm the diagnosis of $\mathrm{VaD}$. Appropriate statistical analyses should be carried out for baseline data and outcome results; long-term followup is also recommended and highly desirable.

Our review has identified the individual herbs that appear most frequently in formulas for $\mathrm{VaD}$. The top five are Rhizoma Chuanxiong (Chuanxiong), Radix Polygoni Multiflori (Heshouwu), Radix Astragali (Huangqi), Radix Ginseng (Renshen), and Rhizoma Acori Talarinowii (Shichangpu). The clinical efficacy and safety of these herbs, over centuries of use and during recent controlled studies, are a powerful combination of attributes. We believe that further highquality clinical studies on these individual constituents, as well as the herbal mixtures resulted, could lead to the discovery of new drugs for effective treatment and prevention of $\mathrm{VaD}$.

\section{Conclusion}

Currently available RCTs suggested that HM might be more effective and safer than OM for treatment of $\mathrm{VaD}$. However, these studies have a number of weaknesses, mainly due to their methodological insufficiencies. With regard to the reports that did meet our selection criteria, the results indicated that HM, in a predominance of instances, can be superior to $\mathrm{OM}$ and useful in the treatment of VaD. Further multicenter trials with large sample sizes, high methodological quality, and standardized HM ingredients are needed to confirm the value of $\mathrm{HM}$ in treating $\mathrm{VaD}$, in order to establish specific clinical recommendations.

\section{Acknowledgments}

The paper was supported by research Grant FRG/08-09/I01 from Hong Kong Baptist University, and also partly by research grant EYS/07-08/01 from Eu Yan Sang (Hong
Kong) Limited. The authors especially thank Ms. WaiSheung Chan, Ms. Loretta Ho, and the Lions Club of South Kowloon, Hong Kong for their further financial support of this paper. They would also like to thank Dr. Martha Dahlen for her critical review and revision.

\section{References}

[1] J. Quinn, "Vascular dementia," Journal of the American Medical Directors Association, vol. 4, no. 6, pp. S155-S161, 2003.

[2] F. E. de Leeuw and J. van Gijn, "Vascular dementia," Practical Neurology, vol. 3, no. 2, pp. 86-91, 2003.

[3] K. A. Jellinger, "The pathology of "vascular dementia": a critical update," Journal of Alzheimers Disease, vol. 14, no. 1, pp. 107-123, 2008.

[4] G. C. Román, "Vascular dementia: distinguishing characteristics, treatment, and prevention," Journal of the American Geriatrics Society, vol. 51, no. 5, pp. S296-S304, 2003.

[5] F. Hentschel, T. Supprian, and L. Frölich, "Alzheimer's disease versus vascular dementia-dichotomy or interaction?" Fortschritte der Neurologie Psychiatrie, vol. 73, no. 6, pp. 317326, 2005.

[6] M. J. Schneck, "Vascular dementia," Topics in Stroke Rehabilitation, vol. 15, no. 1, pp. 22-26, 2008.

[7] R. Moretti, P. Torre, R. M. Antonello, and G. Cazzato, "Behavioral alterations and vascular dementia," Neurologist, vol. 12 , no. 1, pp. 43-47, 2006.

[8] K. A. Swanson and R. M. Carnahan, "Dementia and comorbidities: an overview of diagnosis and management," Journal of Pharmacy Practice, vol. 20, no. 4, pp. 296-317, 2007.

[9] B. Schneider, K. Maurer, and L. Frölich, "Dementia and suicide," Fortschritte der Neurologie Psychiatrie, vol. 69, no. 4, pp. 164-169, 2001.

[10] R. N. Kalaria, G. E. Maestre, R. Arizaga et al., "Alzheimer's disease and vascular dementia in developing countries: prevalence, management, and risk factors," The Lancet Neurology, vol. 7, no. 9, pp. 812-826, 2008.

[11] R. Kalaria, "Similarities between Alzheimer's disease and vascular dementia," Journal of the Neurological Sciences, vol. 203-204, pp. 29-34, 2002.

[12] C. McVeigh and P. Passmore, "Vascular dementia: prevention and treatment," Clinical Interventions in Aging, vol. 1, no. 3, pp. 229-235, 2006.

[13] M. J. Dong, B. Peng, X. T. Lin, J. Zhao, Y. R. Zhou, and R. H. Wang, "The prevalence of dementia in the People's Republic of China: a systematic analysis of 1980-2004 studies," Age and Ageing, vol. 36, no. 6, pp. 619-624, 2007.

[14] C. K. Andersen, J. Søgaard, E. Hansen et al., "The cost of dementia in Denmark: the Odense study," Dementia and Geriatric Cognitive Disorders, vol. 10, no. 4, pp. 295-304, 1999.

[15] J. Hill, H. Fillit, S. N. Shah, M. C. del Valle, and R. Futterman, "Patterns of healthcare utilization and costs for vascular dementia in a community-dwelling population," Journal of Alzheimer's Disease, vol. 8, no. 1, pp. 43-50, 2005.

[16] R. Moretti, P. Torre, R. M. Antonello, C. Vilotti, and G. Pizzolato, "New treatment options for vascular dementia," Aging Health, vol. 3, no. 2, pp. 209-222, 2007.

[17] D. Zekry, "Is it possible to treat vascular dementia?" Frontiers of Neurology and Neuroscience, vol. 24, pp. 95-106, 2009. 
[18] A. Baskys and A. C. Hou, "Vascular dementia: pharmacological treatment approaches and perspectives," Clinical Interventions in Aging, vol. 2, no. 3, pp. 327-335, 2007.

[19] L. Pantoni, "Treatment of vascular dementia: evidence from trials with non-cholinergic drugs," Journal of the Neurological Sciences, vol. 226, no. 1-2, pp. 67-70, 2004.

[20] G. Sorrentino, R. Migliaccio, and V. Bonavita, "Treatment of vascular dementia: the route of prevention," European Neurology, vol. 60, no. 5, pp. 217-223, 2008.

[21] B. C. Stephan and C. Brayne, "Vascular factors and prevention of dementia," International Review of Psychiatry, vol. 20, no. 4, pp. 344-356, 2008.

[22] N. Perry, G. Court, N. Bidet, J. Court, and E. Perry, "European herbs with cholinergic activities: potential in dementia therapy," International Journal of Geriatric Psychiatry, vol. 11, no. 12, pp. 1063-1069, 1996.

[23] E. Yarnell, "Lemonbalm: humble but potent herb," Alternative and Complementary Therapies, vol. 4, pp. 417-419, 1998.

[24] B. V. Manyam, "Dementia in Ayurveda," Journal of Alternative and Complementary Medicine, vol. 5, no. 1, pp. 81-88, 1999.

[25] R. Upton, Ashwagandha Root. Withania Somnifera. Analytical, Quality Control and Therapeutic Monograph, American Herbal Pharmacopoeia and Therapeutic Compendium, 200.

[26] M. J. Howes, N. S. Perry, and P. J. Houghton, "Plants with traditional uses and activities, relevant to the management of Alzheimer's disease and other cognitive disorders," Phytotherapy Research, vol. 17, no. 1, pp. 1-18, 2003.

[27] H. Chang and P. P. But, Pharmacology and Applications of Chinese Materia Medica, vol. 2, World Scientific, Singapore, 1987.

[28] D. Kenner and Y. Requena, Botanical Medicine: A European Professional Perspective, Paradigm, Brookline, Mass, USA, 1996.

[29] F. Boughon, "Herbs for the elderly," Australian Journal of Medical Herbalism, vol. 10, pp. 51-60, 1998.

[30] S. Zbinden and C. Seiler, "Phytotherapy in cardiovascular medicine," Therapeutische Umschau, vol. 59, no. 6, pp. 301306, 2002.

[31] V. Klusa, S. Germane, M. Nöldner, and S. S. Chatterjee, "Hypericum extract and hyperforin: memory-enhancing properties in rodents," Pharmacopsychiatry, vol. 34, no. 1, pp. S61S69, 2001.

[32] W. Y. Tam, P. Chook, M. Qiao et al., "The efficacy and tolerability of adjunctive alternative herbal medicine (Salvia miltiorrhiza and Pueraria lobata) on vascular function and structure in coronary patients," Journal of Alternative and Complementary Medicine, vol. 15, no. 4, pp. 415-421, 2009.

[33] J. Cai, F. Zhou, and J. Du, "Effects of glossy privet fruit on neural cell apoptosis in the cortical parietal lobe and hippocampal CA1 region of vascular dementia rats," Neural Regeneration Research, vol. 3, no. 11, pp. 1192-1196, 2008.

[34] K. Cho, K. Noh, W. Jung et al., "A preliminary study on the inhibitory effect of Chunghyul-dan on stroke recurrence in patients with small vessel disease," Neurological Research, vol. 30, no. 6, pp. 655-658, 2008.

[35] R. Wang, H. Yan, and X. C. Tang, "Progress in studies of huperzine A, a natural cholinesterase inhibitor from Chinese herbal medicine," Acta Pharmacologica Sinica, vol. 27, no. 1, pp. 1-26, 2006.

[36] S. C. Man, S. S. Durairajan, W. F. Kum et al., "Systematic review on the efficacy and safety of herbal medicines for Alzheimer's disease," Journal of Alzheimer's Disease, vol. 14, no. 2, pp. 209-223, 2008.
[37] A. Viswanathan, W. A. Rocca, and C. Tzourio, "Vascular risk factors and dementia: how to move forward?" Neurology, vol. 72, no. 4, pp. 368-374, 2009.

[38] M. E. Murray, D. S. Knopman, and D. W. Dickson, "Vascular dementia: clinical, neuroradiologic and neuropathologic aspects," Panminerva Medica, vol. 49, no. 4, pp. 197-207, 2007.

[39] American Psychiatric Association, Diagnostic and Statistical Manual of Mental Disorders: DSM-III-R, American Psychiatric Association, Washington, DC, USA, 1987.

[40] American Psychiatric Association, Diagnostic and Statistical Manual of Mental Disorders: DSM-IV, American Psychiatric Association, Washington, DC, USA, 1994.

[41] World Health Organization, The ICD-10 Classification of Mental and Behavioural Disorders : Clinical Descriptions and Diagnostic Guidelines, World Health Organization, Geneva, Switzerland, 1992.

[42] H. C. Chui, J. I. Victoroff, D. Margolin, W. Jagust, R. Shankle, and R. Katzman, "Criteria for the diagnosis of ischemic vascular dementia proposed by the State of California Alzheimer's Disease Diagnostic and Treatment Centers," Neurology, vol. 42, no. 3 I, pp. 473-480, 1992.

[43] V. C. Hachinski, L. D. Iliff, and E. Zilhka, "Cerebral blood flow in dementia," Archives of Neurology, vol. 32, no. 9, pp. 632-637, 1975.

[44] G. C. Roman, T. K. Tatemichi, T. Erkinjuntti et al., "Vascular dementia: diagnostic criteria for research studies: report of the NINDS-AIREN International Workshop," Neurology, vol. 43, no. 2, pp. 250-260, 1993.

[45] M. F. Folstein, S. E. Folstein, and P. R. McHugh, "Mini mental state'. A practical method for grading the cognitive state of patients for the clinician," Journal of Psychiatric Research, vol. 12, no. 3, pp. 189-198, 1975.

[46] S. Katz, "Activities of daily living scale," Home Health Care Services Quarterly, vol. 25, no. 1-2, pp. 13-31, 2006.

[47] N. Tsai and Z. X. Gao, "Validity of Hasegawa's dementia scale for screening dementia among aged Chinese," International Psychogeriatrics, vol. 1, no. 2, pp. 145-152, 1989.

[48] W. Zhang, T. Leonard, F. Bath-Hextall et al., "Chinese herbal medicine for atopic eczema," Cochrane Database of Systematic Reviews, no. 3, 2007.

[49] D. Moher, K. F. Schulz, and D. G. Altman, "The CONSORT statement: revised recommendations for improving the quality of reports of parallel-group randomised trials," Lancet, vol. 357, no. 9263, pp. 1191-1194, 2001.

[50] D. Moher, K. F. Schulz, and D. G. Altman, "The CONSORT statement: revised recommendations for improving the quality of reports of parallel-group randomised trials," Clinical Oral Investigations, vol. 7, no. 1, pp. 2-7, 2003.

[51] C. Q. Zhang, Y. L. Jin, and L. J. Zhao, "Clinical study on Jian Nao Tong Luo Jiao Nang in the treatment of vascular dementia," Chinese Journal of Information on Traditional Chinese Medicine, vol. 8, pp. 51-52, 2001.

[52] F. J. Wang, S. J. Lu, and Z. Dong, "Clinical study on Yi Zhi Tong Luo Jiao Nang in the treatment of vascular dementia," Modern Journal of Integrated Chinese Traditional and Western Medicine, vol. 11, pp. 295-297, 2002.

[53] X. F. Guo, Y. B. Yan, Y. H. Zhao, and C. X. Sun, "Clinical study on Bu Nao Tong Qiao Fang in the treatment of vascular dementia," Journal of Traditional Chinese Medicine, vol. 44, p. 931, 2003.

[54] M. L. Hong, G. D. Hou, L. S. Hong et al., "Clinical study on Shou Xing Jiao Nang in the treatment of vascular dementia," 
Hubei Journal of Traditional Chinese Medicine, vol. 24, pp. 3$5,2002$.

[55] Z. G. Luo, W. Q. Zhou, P. Gao, and L. Cui, "Clinical study on treatment of senile vascular dementia with Shen Ma Yi Zhi capsule," Journal of Traditional Chinese Medicine, vol. 42, pp. 470-473, 2001.

[56] F. W. Wang, Z. K. Wang, N. Jiang et al., "Clinical study on the effect of shenlong decoction on vascular dementia," Academic Journal of PLA Postgraduate Medical School, vol. 26, pp. 9395, 2005.

[57] H. He, "Clinical study on Yi Shen Hua Zhuo Qu Yu Zhu Tan Fa in the treatment of vascular dementia," Chinese Journal of Information on Traditional Chinese Medicine, vol. 14, pp. 6061, 2007.

[58] Q. Yan, "Clinical study on Chinese medicine in the treatment of vascular dementia," Journal of Sichuan of Traditional Medicine, vol. 25, pp. 41-42, 2007.

[59] H. Ji, "Clinical observation on the treatment of vaseular dementia by Danggui Shaoyao powder," Shanxi Journal of Traditional Chinese Medicine, vol. 16, pp. 10-11, 2000.

[60] H. J. Liu, J. Qin, W. Liang, and Y. Q. Huang, "Clinical study on Hua Tuo Zai Zao Wan in the treatment of vascular dementia," Chinese Traditional and Herbal Drugs, vol. 36, pp. 1052-1054, 2005.

[61] L. J. Li, L. T. Zhang, Y. M. Li, and D. S. Shang, "Clinical study on Tong Mai Yi Zhi Wan in the treatment of vascular dementia," Journal of Hubei College of Traditional Chinese Medicine, vol. 8, pp. 48-49, 2006.

[62] F. W. Wang, N. Jiang, Z. Q. Tong et al., "Clinical study on shenlong tang for improving neurological impairment in patients with vascular dementia," Chinese Journal of Clinical Rehabilitation, vol. 8, no. 4, pp. 679-681, 2004.

[63] Y. Wan and Y. F. Wang, "Clinical study on effect of fucongtang in treating vascular dementia," Hebei Medicine, vol. 4, pp. 2427, 1998.

[64] G. P. Zhou and X. Yi, "Clinical study on Yi Nao Ling in the treatment of vascular dementia," Shandong Journal of Traditional Chinese Medicine, vol. 20, pp. 14-15, 2001.

[65] C. Z. Liu, L. H. Zhou, and Z. Shui, "Clinical study on Tong Qiao Huo Xue Tang He Bu Yang Huan Wu Tang in the treatment of vascular dementia," Journal of Traditional Chinese Medicine, vol. 43, pp. 526-527, 2002.

[66] S. Z. Yu, G. S. Zheng, Q. Shi, L. X. Ai, and R. R. Cheng, "Clinical study on Fucong Xiangye for treatment of 72 cases of vascular dementia," Journal of Traditional Chinese Medicine, vol. 45, pp. 424-425, 2004.

[67] Q. Gao, "Clinical study on Shu Mai Yi Nao Jiao Nang in the treatment of vascular dementia," Forum on Traditional Chinese Medicine, vol. 21, pp. 14-16, 2006.

[68] W. H. Mou, "Clinical observation of Yizhi decoction treating senile vascular dementia," Liaoning Journal of Traditional Chinese Medicine, vol. 33, p. 1607, 2006.

[69] W. Y. Zhang and Z. P. Lu, "Clinical study on effect of Bushenjiannao decoction in vascular dementia patients," Chinese Journal of Integrative Medicine on Cardio-/Cerebrovascular Disease, vol. 4, pp. 680-681, 2006.

[70] Z. Y. Chang, Q. C. Qiao, Y. H. Zhang, and Q. Z. Qiao, "Clinical study on Qi Hong Kou Fu Ye in the treatment of vascular dementia," Chinese Remedies \& Clinics, vol. 8, pp. 240-241, 2008.

[71] G. T. Liu, "Changes of intellectual status, hemorheology and blood lipids in patients with vascular dementia and the interventional effects of Bushen Yinao capsule," Chinese
Journal of Clinical Rehabilitation, vol. 9, no. 20, pp. 50-51, 2005.

[72] J. Cai, J. Du, J. S. Huang, and Q. C. Lin, "Clinical effect of the principle of tonifying-kidney, invigorating-spleen, nourishing and activating-blood on patients with vascular dementia," Chinese Journal of Clinical Rehabilitation, vol. 7, no. 31, pp. 4251-4253, 2003.

[73] X. L. Liao, K. Y. Chen, Z. R. Zheng, H. Liu, and K. Y. Zheng, "Clinical study of Shoulingjiannao capsule in improvement of brain function for patients with vascular dementia," Chinese Journal of Clinical Rehabilitation, vol. 8, no. 1, pp. 112-114, 2004.

[74] W. Liu and Z. Y. Chen, "Clinical study of shulzhltong capsule in treating senile vascular dementia," China and Foreign and Medical Journal, vol. 3, pp. 18-20, 2005.

[75] X. J. Tang, Y. R. Lao, Z. M. Yang, P. X. Huang, and X. D. Luo, "Clinical observation on modified bushen huoxie decoction for the treatment of vascular dementia," Journal of Guangzhou University of Traditional Chinese Medicine, vol. 22, pp. 426-429, 2005.

[76] H. Shi and H. M. Wang, "Clinical effects observation of invigorating kidney and promoting blood flow method on treating vascular dementia," Tianjin Journal of Traditional Chin Medicine, vol. 23, pp. 200-202, 2006.

[77] L. Cui, F. Liu, and M. D. Guo, "Clinical study on Shuang Shen $\mathrm{Cu} \mathrm{Zhi} \mathrm{Ke} \mathrm{Li}$ in the treatment of vascular dementia," China Journal of Experimental Traditional Medical Formulae, vol. 13, pp. 64-65, 2007.

[78] Y. P. Li and Z. D. Shi, "Clinical study on Bu Yang Huan Wu Tang in the treatment of vascular dementia," Journal of Hubei College of Traditional Chinese Medicine, vol. 1, pp. 17-18, 1999.

[79] Y. Zhao, W. Zhou, and P. Gao, "Clinical study on effect of xianlong capsule on senile vascular dementia," Chinese Journal of Integrated Traditional and Western Medicine, vol. 19, no. 10, pp. 585-588, 1999.

[80] W. M. Yang, W. J. Lu, M. X. Han et al., "Clinical research of Zhinao capsule on 60 cases with vascular dementia," China Journal of Experimental Traditional Medical Formulae, vol. 8, pp. 48-51, 2002.

[81] J. Cai, J. Du, J. S. Huang, Q. C. Lin, and K. J. Chen, "Clinical observation of Kangxin capsule on the influence of vascular dementia," Chinese Journal of Gerontology, vol. 23, pp. 482484, 2003.

[82] X. L. Cao, X. X. Song, Z. Q. Hu, T. Mei, J. Zhou, and F. R. Zhang, "Clinical study on treatment of vascular dementia with congsheng capsule," Journal of Emergency in Traditional Chinese Medicine, vol. 11, pp. 80-81, 2002.

[83] S. Y. Wu, S. Q. Fang, and H. Liang, "Clinical study on Cong Rong Zong Dai Jiao Nang in the treatment of vascular dementia," Fujian Journal of Traditional Chinese Medicine, vol. 35, pp. 3-4, 2004.

[84] L. P. Chen, F. W. Wang, J. J. Jia, and A. J. Hao, "Effects of shenlong decoction on life quality of the aged patients with cerebral vascular dementia," Medical Journal of Chinese People's Liberation Army, vol. 32, pp. 866-868, 2007.

[85] X. M. Jin, L. Li, L. X. Lian, and Z. H. Song, "Clinical investigation of Jiannaoyizhi capsule to improving vascular dementia sufferer on nerve function damage," Chinese Archives of Traditional Chinese Medicine, vol. 25, pp. 16571659, 2007.

[86] Y. Y. Feng, J. X. Zhang, and X. D. Ding, "Clinical study on Yi Zhi Tang in the treatment of vascular dementia," Study 
Journal of Traditional Chinese Medicine, vol. 23, pp. 520-522, 2005.

[87] J. C. Morris, "The clinical dementia rating (CDR): current version and scoring rules," Neurology, vol. 43, no. 11, pp. 2412-2414, 1993.

[88] J. Z. Tian, X. H. Ming, W. T. Jin et al., "Criteria for the diagnosis, the differentiation of syndrome and the evaluation of efficacy of vascular dementia for research studies," Chinese Journal of Gerontology, vol. 22, pp. 329-331, 2002.

[89] G. G. Fillenbaum and M. A. Smyer, "The development, validity, and reliability of the OARS multidimensional functional assessment questionnaire," Journals of Gerontology, vol. 36, no. 4, pp. 428-434, 1981.

[90] H. Lu, Y. Y. Wang, F. Chen, Y. Wu, D. H. Gai, and Z. Cui, "Clinical observation on 50 cases of cerebrovascular dementia treated with Shentong capsule," J TCM, vol. 41, pp. 290-291, 2000.

[91] Q. H. Huang, Q. M. Li, and Z. H. Tan, "Clinical study on naohuandan capsule in the treatment of senile dementia," Practical Geriatrics, vol. 16, pp. 301-304, 2002.

[92] W. H. Jia, X. N. Ding, Z. M. Xu, and M. P. Jie, "Clinical study on the Luoshukang Capsule in the treatment of vascular dementia [Luoshukang Jiao Nang Zhi Liao Xue Guan Xing Chi Dai De Lin Chuang Yan Jiu]," Guang Ming Zhong Yi, vol. 18, pp. 20-22, 2003.

[93] W. P. Cheng, L. Ma, H. Toshihide, and Q. W. Wang, "Treatment of Vascular Dementia by Naozhitong Capsule: A Clinical Observation of 18 Cases," J New CM, vol. 36, pp. 16$18,2004$.

[94] S. H. Shen and J. Du, "The therapeutic effects of KidneyTonifying and spleen-invigorating, blood-nourishing and quickening the blood formula on vascular dementia in the pattern of Kidney deficiency and blood stasis," J TCM U HUNAN, vol. 24, pp. 41-50, 2004.

[95] F. W. Wang, N. Jiang, Z. Q. Tong et al., "Clinical study on Shenlong Tang for improving neurological impairment in patients with vascular dementia," CHIN J CLIN REHAB, vol. 8, pp. 679-681, 2004.

[96] J. Wang, Q. X. Chen, Y. Hai et al., "Clinical Study of Huitianpian in the treatment of vascular dementia," Chinese Archieves of Traditional Chinese Medicine, vol. 22, no. 9, pp. 1691-1694, 2004.

[97] Y. J. Zhao, "A Summary on 50 Cases of Vascular Dementia Treated by Jiannao Qingxin Decoction," HUNAN J TRAD CHIN MED, vol. 6, pp. 8-10, 2004.

[98] J. Wang, Q. W. Chen, and L. Bai, "Clinical study of Jiannaocongming decoction in the treatment of vascular dementia [Jiannaocongming Kou Fu Ye Zhi Liao Xue Guan Xing Chi Dai De Lin Chuang Yan Jiu]," LIAONING J TCM, vol. 32, pp. 3-5, 2005.

[99] L. L. Wang, P. Z. Ying, and X. M. Wang, "Clinical efficacy of Tongxinluo capsule in the treatment of vascular dementia," CHIN J DIFFIC COMPL CAS, vol. 4, pp. 260-262, 2005.

[100] Z. Y. Wang, "Clinical observation of Buyanghuanwutang in the treatment of vascular dementia [Buyanghuanwutang jia xi yao zhi liao xue guan xing chi dai liao xiao guan cha]," $J$ SICHUAN TRAD CHIN MED, vol. 23, pp. 40-41, 2005.

[101] J. Y. Zhou, T. Liu, and C. C. Sun, "Clinical Study on "Yiqi Fuzhi Granule” in Treating Vascular Dementia," SHANGHAI J TRAD CHIN MED, vol. 39, pp. 11-13, 2005.

[102] W. P. Hao, F. H. Ye, and L. Z. Li, "Clinical observations of Tongxingluo capsule in the treatment of vascular dementia," J CLIN PSYCHOSOM DIS, vol. 12, pp. 424-425, 2006.
[103] C. S. Li, J. Li, X. H. Guan et al., "Clinical study of Shouwuyizhi capsule in the treatment of vascular dementia," CHIN J GERI, vol. 28, pp. 369-371, 2008.

[104] Z. Q. Quan et al., "Progress on the TCM diagnosis and treatment of vascular dementia," Acta Chinese Medicine and Pharmacology, vol. 5, p. 52, 1996.

[105] Guidance Principle of Clinical Study on New Drug of Traditional Chinese Medicine, vol. 2, Ministry of Health of the People's Republic of China, Beijing, China.

[106] R. J. Fu, "TCM diagnostic criteria, differentiation and outcome measures on senile dementia," Journal of Traditional Chinese Medicine, vol. 2, p. 56, 1991.

[107] W. Q. Zhou, "Protocol for the selection of anti-aging herbal medicine and the corresponding outcome measures," Chinese Journal of Integrated and Traditional and Western Medicine, vol. 11, p. 683, 1986.

[108] P. X. Huang and M. C. Liu, TCM manual for neurological diseases, People's Medical Publishing House, Beijing, China, 2000.

[109] X. D. Wang, Diagnostic manual for geriatrics, Peking Union Medical College Press, Beijing, China, 1997.

[110] S. Dharmananda, "Alzheimer's disease: treatment with Chinese herbs," 1996.

[111] L. Xiong, Z. Y. Fang, X. N. Tao, M. Bai, and G. Feng, "Effect and mechanism of ligustrazine on Th1/Th2 cytokines in a rat asthma model," American Journal of Chinese Medicine, vol. 35, no. 6, pp. 1011-1020, 2007.

[112] D. Cai, "Effectiveness and safety of xiaoshuanchangrong (XSCR) capsule for the treatment of patients who have suffered from a stroke," Fudan University Identifier: NCT00710164, 2008.

[113] S. Ling, L. Nheu, A. Dai, Z. Guo, and P. Komesaroff, "Effects of four medicinal herbs on human vascular endothelial cells in culture," International Journal of Cardiology, vol. 128, no. 3, pp. 350-358, 2008.

[114] Y. C. Chan, M. F. Wang, Y. C. Chen, D. Y. Yang, M. S. Lee, and F. C. Cheng, "Long-term administration of Polygonum multiflorum Thunb. reduces cerebral ischemiainduced infarct volume in gerbils," American Journal of Chinese Medicine, vol. 31, no. 1, pp. 71-77, 2003.

[115] S. P. Ip, A. S. Tse, M. K. Poon, K. M. Ko, and C. Y. Ma, "Antioxidant activities of Polygonum multiflorum Thunb; in vivo and in vitro," Phytotherapy Research, vol. 11, no. 1, pp. 42-44, 1997.

[116] M. Y. Um, W. H. Choi, J. Y. Aan, S. R. Kim, and T. Y. $\mathrm{Ha}$, "Protective effect of Polygonum multiflorum Thunb on amyloid $\beta$-peptide 25-35 induced cognitive deficits in mice," Journal of Ethnopharmacology, vol. 104, no. 1-2, pp. 144-148, 2006.

[117] Y. C. Chan, F. C. Cheng, and M. F. Wang, "Beneficial effects of different Polygonum multiflorum Thunb. Extracts on memory and hippocampus morphology," Journal of Nutritional Science and Vitaminology, vol. 48, no. 6, pp. 491-497, 2002.

[118] M. J. Chiu, "Efficacy and safety study of DCB-AD1 in patients with mild to moderate Alzheimer's disease," National Taiwan University Hospital Identifier: NCT00154635, 2005.

[119] Z. J. Zhang, "Therapeutic effects of herbal extracts and constituents in animal models of psychiatric disorders," Life Sciences, vol. 75, no. 14, pp. 1659-1699, 2004.

[120] Q. Zhang, Z. Chang, J. Yang, and Q. Wang, "Antiatherogenic property of triterpenoids-enriched extract from the aerial parts of Salvia miltiorrhiza," Phytotherapy Research, vol. 22, no. 8 , pp. 1040-1045, 2008. 
[121] C. J. Lao, J. G. Lin, J. S. Kuo et al., "Effect of Salvia Miltiorrhiza Bunge on cerebral infarct in ischemia-reperfusion injured rats," American Journal of Chinese Medicine, vol. 31, no. 2, pp. 191-200, 2003.

[122] G. Zhang, A. Liu, Y. Zhou, X. San, T. Jin, and Y. Jin, "Panax ginseng ginsenoside-Rg2 protects memory impairment via anti-apoptosis in a rat model with vascular dementia," Journal of Ethnopharmacology, vol. 115, no. 3, pp. 441-448, 2007.

[123] Y. C. Huang, C. T. Chen, S. C. Chen et al., "A natural compound (Ginsenoside Re) isolated from Panax ginseng as a novel angiogenic agent for tissue regeneration," Pharmaceutical Research, vol. 22, no. 4, pp. 636-646, 2005.

[124] S. T. Lee, K. Chu, J. Y. Sim, J. H. Heo, and M. Kim, "Panax ginseng enhances cognitive performance in Alzheimer disease," Alzheimer Disease and Associated Disorders, vol. 22, no. 3, pp. 222-226, 2008.

[125] W. P. Liao, L. Chen, Y. H. Yi et al., "Study of antiepileptic effect of extracts from Acorus tatarinowii schott," Epilepsia, vol. 46, supplement 1, pp. 21-24, 2005.

[126] W. Wang, F. Sun, Y. An et al., "Morroniside protects human neuroblastoma SH-SY5Y cells against hydrogen peroxideinduced cytotoxicity," European Journal of Pharmacology, vol. 613, no. 1-3, pp. 19-23, 2009.

[127] C. Li, J. Yang, S. Yu et al., "Triterpenoid saponins with neuroprotective effects from the roots of Polygala tenuifolia," Planta Medica, vol. 74, no. 2, pp. 133-141, 2008.

[128] R. Naito and C. Tohda, "Characterization of antineurodegenerative effects of polygala tenuifolia in abeta(2535)-treated cortical neurons," Biological and Pharmaceutical Bulletin, vol. 29, pp. 1892-1896, 2006.

[129] B. S. Koo, W. C. Lee, Y. C. Chang, and C. H. Kim, "Protective effects of alpinae Oxyphyllae fructus (Alpinia oxyphylla MIQ) water-extracts on neurons from ischemic damage and neuronal cell toxicity," Phytotherapy Research, vol. 18, no. 2, pp. 142-148, 2004.

[130] X. Yu, L. An, Y. Wang, H. Zhao, and C. Gao, "Neuroprotective effect of Alpinia oxyphylla Miq. Fruits against glutamateinduced apoptosis in cortical neurons," Toxicology Letters, vol. 144, no. 2, pp. 205-212, 2003.

[131] F. Zhang, J. Zhang, L. Wang, and D. Mao, "Effects of polygonatum sibiricum polysaccharide on learning and memory in a scopolamine-induced mouse model of dementia," Neural Regeneration Research, vol. 3, no. 1, pp. 33-36, 2008.

[132] S. M. Lee, M. Y. Yoon, and H. R. Park, "Protective effects of Paeonia lactiflora pall on hydrogen peroxide-induced apoptosis in PC12 cells," Bioscience, Biotechnology and Biochemistry, vol. 72, no. 5, pp. 1272-1277, 2008.

[133] T. X. Zhang, C. Q. Niu, H. E. Jing, and H. Liu, "Effect of water decoction of the Gastrodia elata BI on vasodilation of rabbit aorta in vitro," Journal of Clinical Rehabilitative Tissue Engineering Research, vol. 12, no. 20, pp. 3988-3991, 2008.

[134] E. K. Ahn, H. J. Jeon, E. J. Lim, H. J. Jung, and E. H. Park, "Anti-inflammatory and anti-angiogenic activities of Gastrodia elata Blume," Journal of Ethnopharmacology, vol. 110, no. 3, pp. 476-482, 2007.

[135] J. H. Liu, Y. M. Bao, J. J. Song, and L. J. An, "Codonopsis pilosula (Franch) Nannf total alkaloids potentiate neurite outgrowth induced by nerve growth factor in PC12 cells," Acta Pharmacologica Sinica, vol. 24, no. 9, pp. 913-917, 2003.

[136] P. T. H. Julian and G. Sally, "Summarizing effects across studies," in Cochrane Handbook for Systematic Reviews of Interventions, J. D. Jonathan, P. T. H. Julian, and G. A. Douglas, Eds., pp. 263-275, Wiley, 2008. 


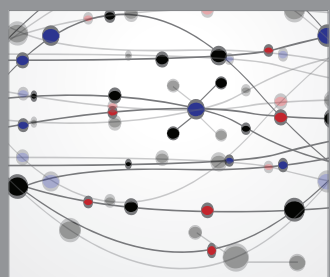

The Scientific World Journal
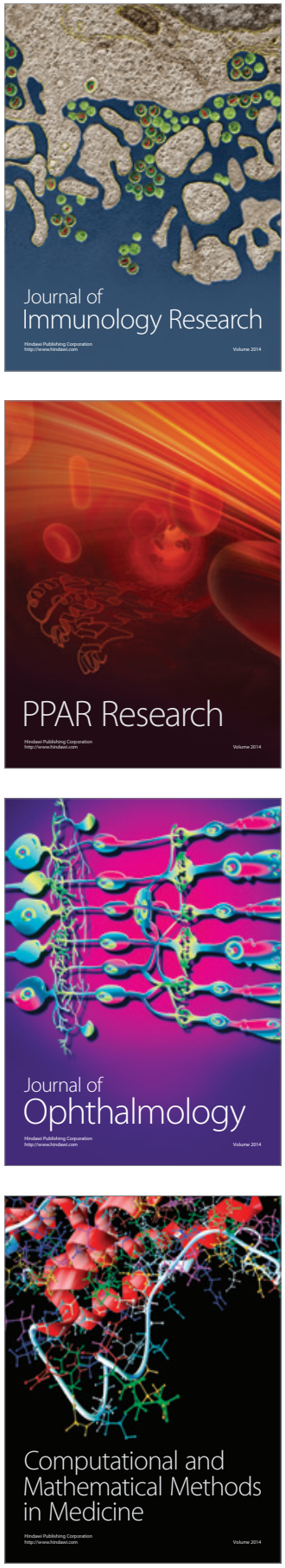

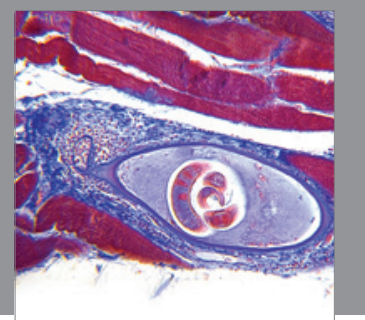

Gastroenterology

Research and Practice
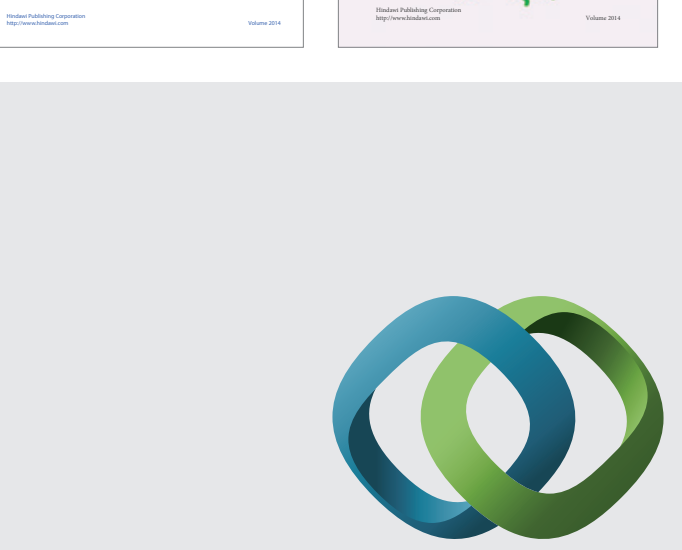

\section{Hindawi}

Submit your manuscripts at

http://www.hindawi.com
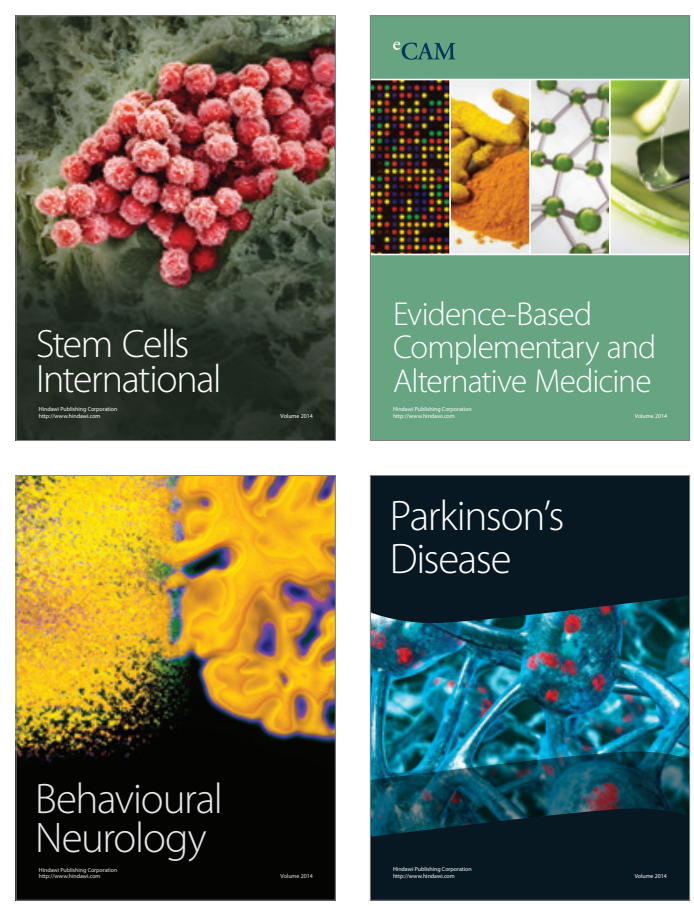

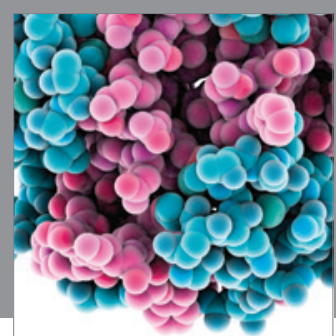

Journal of
Diabetes Research

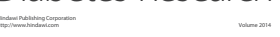

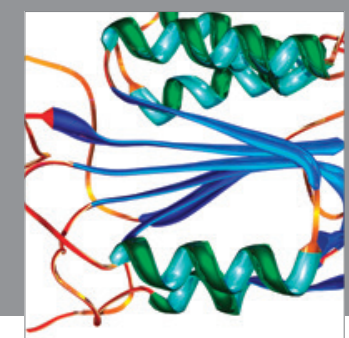

Disease Markers
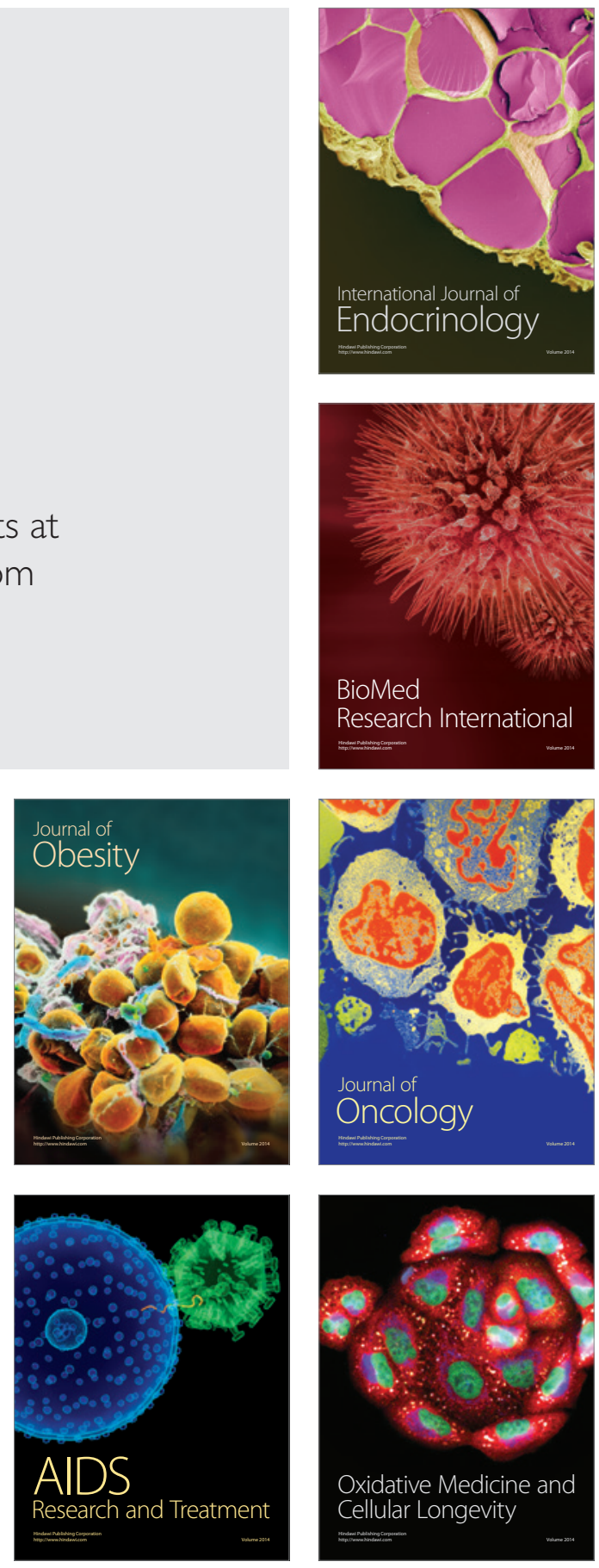